SUPERCONDUCTING QUADRUPOLES*

A. D. McInturff

July 1985

*1985 Summer Workshop, Continuous Electron Beam Accelerator Facility, CEBAF, Newport News, Virginia, June 3-7, 1985 


\title{
SUPERCONDUCTING QUADRUPOLES
}

\author{
A.D. McInturff \\ Fermi National Accelerator Laboratory* \\ P.0. Box 500 \\ Batavia, Illinois 60510
}

\begin{abstract}
The data base for this paper will represent the work from two different groups and two different Laboratories (Brookhaven National Laboratory and Fermi National Accelerator Laboratory). The majority of the data was that obtained by the Fermi National Accelerator Group and is the most recent, and is based on a larger number of coil windings. The coil winding sizes that will be discussed are $12 \mathrm{~cm}$, (Figure 1) $7.6 \mathrm{~cm}$ and $5 \mathrm{~cm}$, (Figure 2) for the inner diameter.
\end{abstract}

The maximum gradients measured in the $5 \mathrm{~cm}$ sizes were $1.93 \mathrm{~T} / \mathrm{cm}$ at $3.5 \mathrm{~K}$ and $1.79 \mathrm{~T} / \mathrm{cm}$ at $4.2 \mathrm{~K} .^{1}$ In the $7.6 \mathrm{~cm}$ size were $1.35 \mathrm{~T} / \mathrm{cm}$ at $2.0 \mathrm{~K}$ and $1.1 \mathrm{~T} / \mathrm{cm}$ at $4.2 \mathrm{~K}^{2}$ and in the $12.0 \mathrm{~cm}$ size was $0.71 \mathrm{~T} / \mathrm{cm}$ at $4.2 \mathrm{~K} .^{3}$ The $12 \mathrm{~cm}$ size used a cold iron shield, but had an older conductor, so one effect (increase due to $\mathrm{Fe}$ ) offset the other (lower $\mathrm{J}_{(\mathrm{H}}(\mathrm{H}$ ) of the earlier superconductor). These gradients (especially the $12 \mathrm{~cm}$ measurements) can be improved using more modern conductors, (i.e.. $-20 \%+\mathrm{g} /(\mathrm{cm} \mathrm{A})$ and their higher current densities. These gradients represent an increase of 2 to $3^{+}$times the value obtainable using conventional iron and copper magnets at a comparable aperature.

The original purposes for these coils were for the $12 \mathrm{~cm}$ size, the Isabelle lattice ${ }^{3}$, the $7.6 \mathrm{~cm}$ size, the Tevatron lattice ${ }^{2}$ and $10 \mathrm{w} B$ insertion focus, and the $5 \mathrm{~cm}$ size, the final focus of SLC at SLAC and SSC size coils. ${ }^{1}$

\section{Materials}

In design calculations of the gradients possible for various quadrupole windings, it becomes obvious that importance of the current density " $J "$ in the winding cross section is much greater in a quadrupole than in a simple bending magnet (i.e., dipole) of comparable aperture. Due to this additional pressure to increase the current density, the normal procedure is to design a quadrupole conductor to have as low a copper volume to superconductor volume as quench protection and operation allows therefore increasing the effective " $\mathrm{J}$ " (winding). This is possible in part because the

*Operated by Universities Research Associations, Inc., under contract with U.S. Department of Energy. 


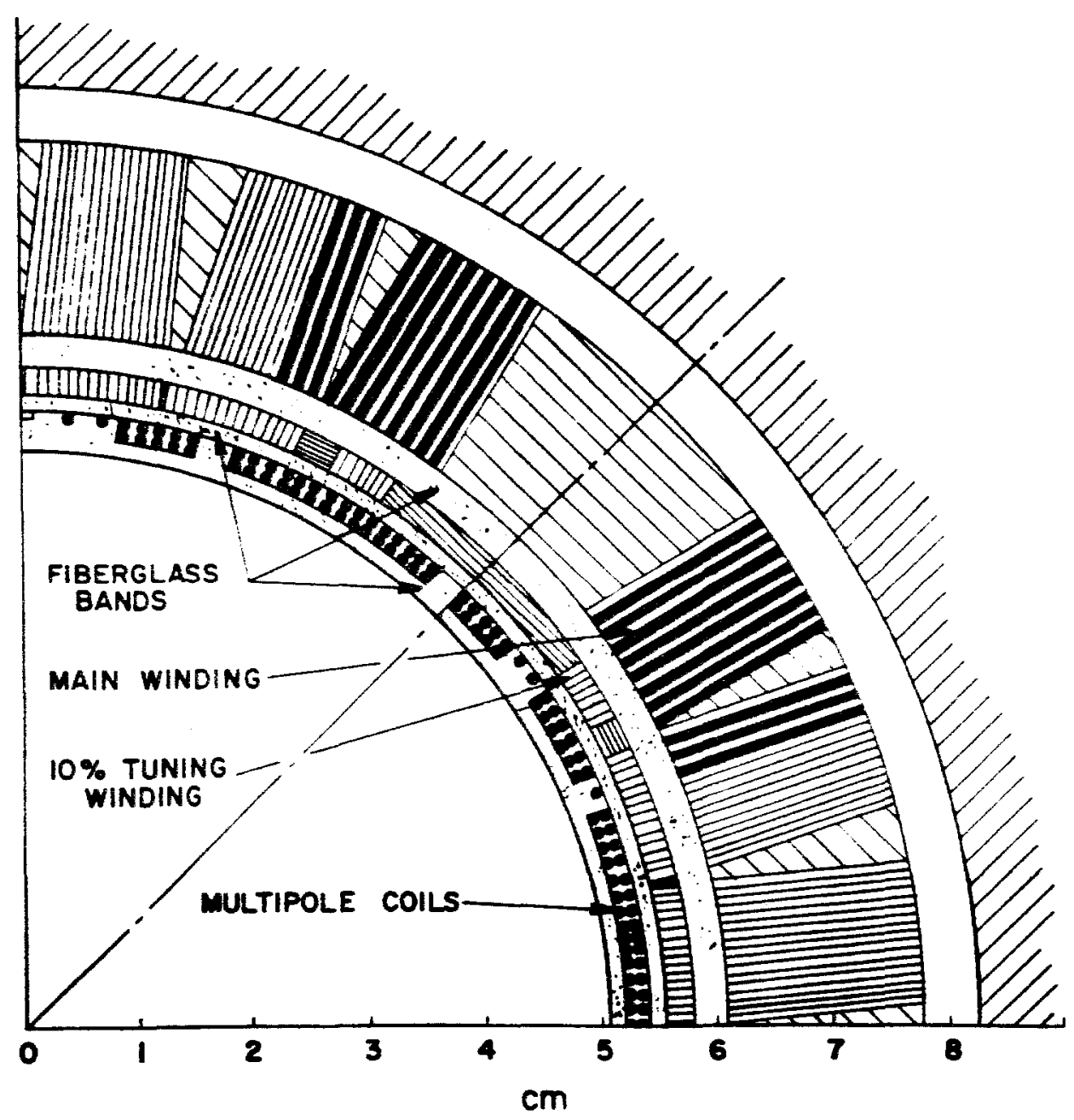

Fig. 1. This is a cross section of an 'ISABELLE' $12.1 \mathrm{~cm}$ aperture quadrupole winding.

inductance of a winding and the total force goes inversely with the pole order and therefore, the voltage necessary for a given rate of current reduction goes inversely with the pole order. The average load on the winding is lower. An example of this are the conductors used in the low " $\beta$ " region of the Tevatron, which have a volume ratio of 1.3 rather than the normal 1.8 that is used in the standard ring magnets. Most applications at present use NbTi based conductors and recentiy due to the microstructure characterization versus critical current density for NbTi based alloys of Larbalestier, West, and co-workers ${ }^{4}$ at the University of Wisconsin, current densities in the normal multi-filamented conductors available have increased by large factors $(\approx 50 \%$ in some cases). Therefore, maximum winding current densities have increased.

In order to understand the parameters available to the designer, the critical surface map of a typical superconductor is studied. (Figure 3) This surface represents the conditions below which 



Fig. 2. Quadrupole winding and collar cross section for a high gradient superconducting coil with a $5 \mathrm{~cm}$ aperture.

superconducting "Cooper" electron pairs can exist in this conductor. The interior plane is defined by the high field point in the winding as a function of it's current for a given amount of superconductor. One variable possible is the percent of the conductor area that is occupied by NbTi (i.e., Cu/NbTi volume ratio). Another possible variable is the winding temperature. The typical plot used by the designer is shown in Figure 4, and represents a plane cut through the critical surface. The conductor curves are shown for $4.25 \mathrm{~K}$, $3.7 \mathrm{~K}$, and $3.2 \mathrm{~K}$ which limit the ultimate gradient possible for this 


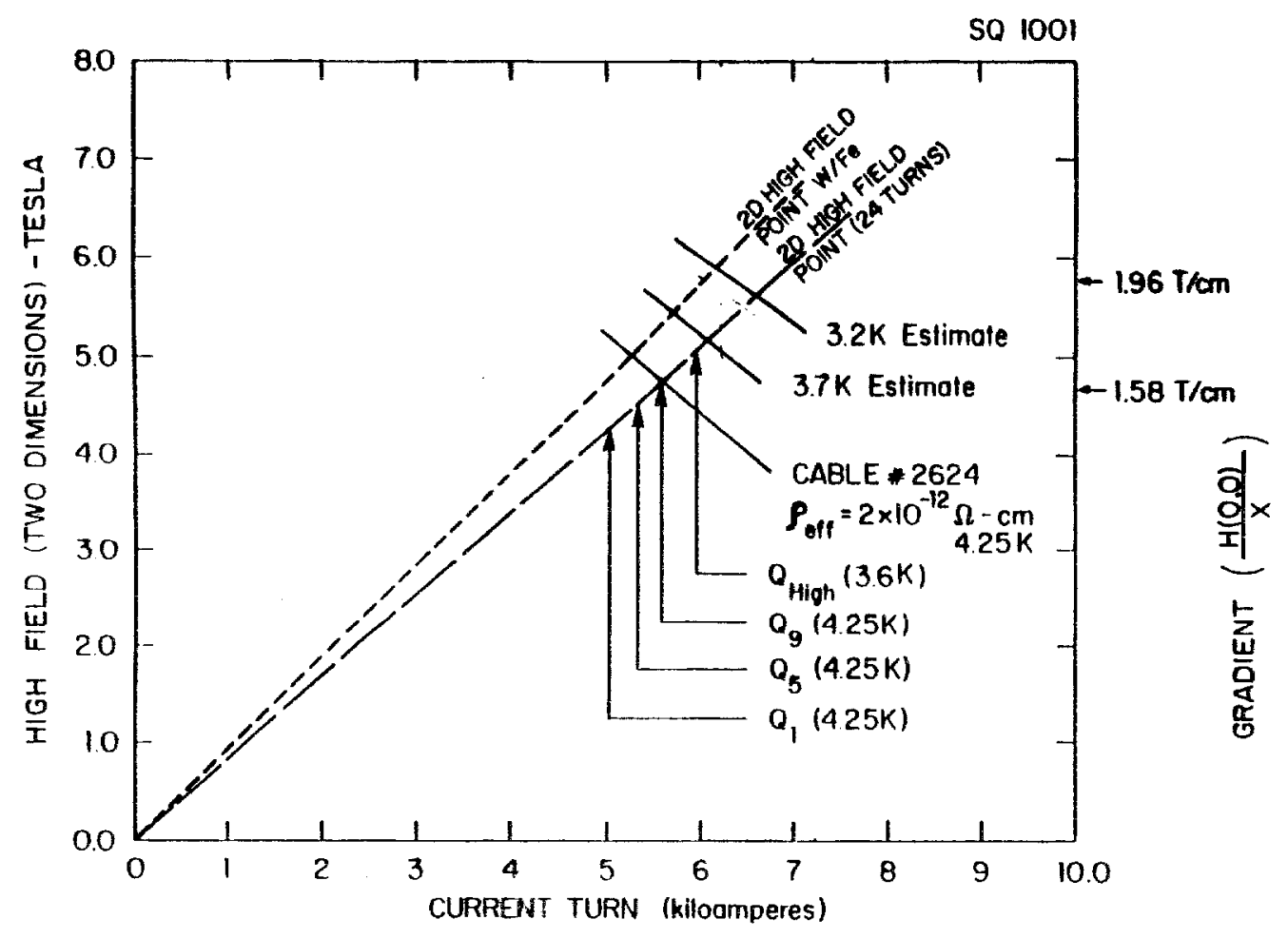

Fig. 4. This is a plot of the peak magnetic field or the gradient on the axis as a funtion of the current. The "Q $Q_{N}$ stands for the ${ }^{n}$ "th superconducting to normal transition under gone by the coil SQ1001 since it was wound.

The first of the modern conductors (as shown in Figures 5 \& 6) is denoted by "SS" SuperSaver symbol. If "SS" cable had been used to wind these coils, the gradient limit would increase to $1.76 \mathrm{~T} / \mathrm{cm}$ at $4.25 \mathrm{~K}$, or if a lower copper to $\mathrm{NbTi}$ volume conductor were used (\#2046), then $1.87 \mathrm{~T} / \mathrm{cm}$ would be the gradient limit at $4.25 \mathrm{~K}$. The latest modern production conductor were substituted for the $1.8 / 1$ ratio material $1.91 \mathrm{~T} / \mathrm{cm}$ is the 1 imit or for the low copper ratio of $1.3 / 1$, it is $2.03 \mathrm{~T} / \mathrm{cm}$. Therefore, the designer has three variables, winding temperature, copper/NoTi volume ratio, and the presence, position, or absence of an iron shield. Table I serves as a reference for a designer, and gives the current densities as a function of field for the standard Tevatron cables. There were nine hundred 5kA standard cables measured, and a few dozen low ' $B$ quad cables (a more modern conductor) measured and used as the data base in Table I.

$5 \mathrm{~cm}$ Aperture Coil Series

The first model series that will be discussed is the $5 \mathrm{~cm}$ aperture versions of quad studies for the SLAC final focus. These models are given in Table II. 


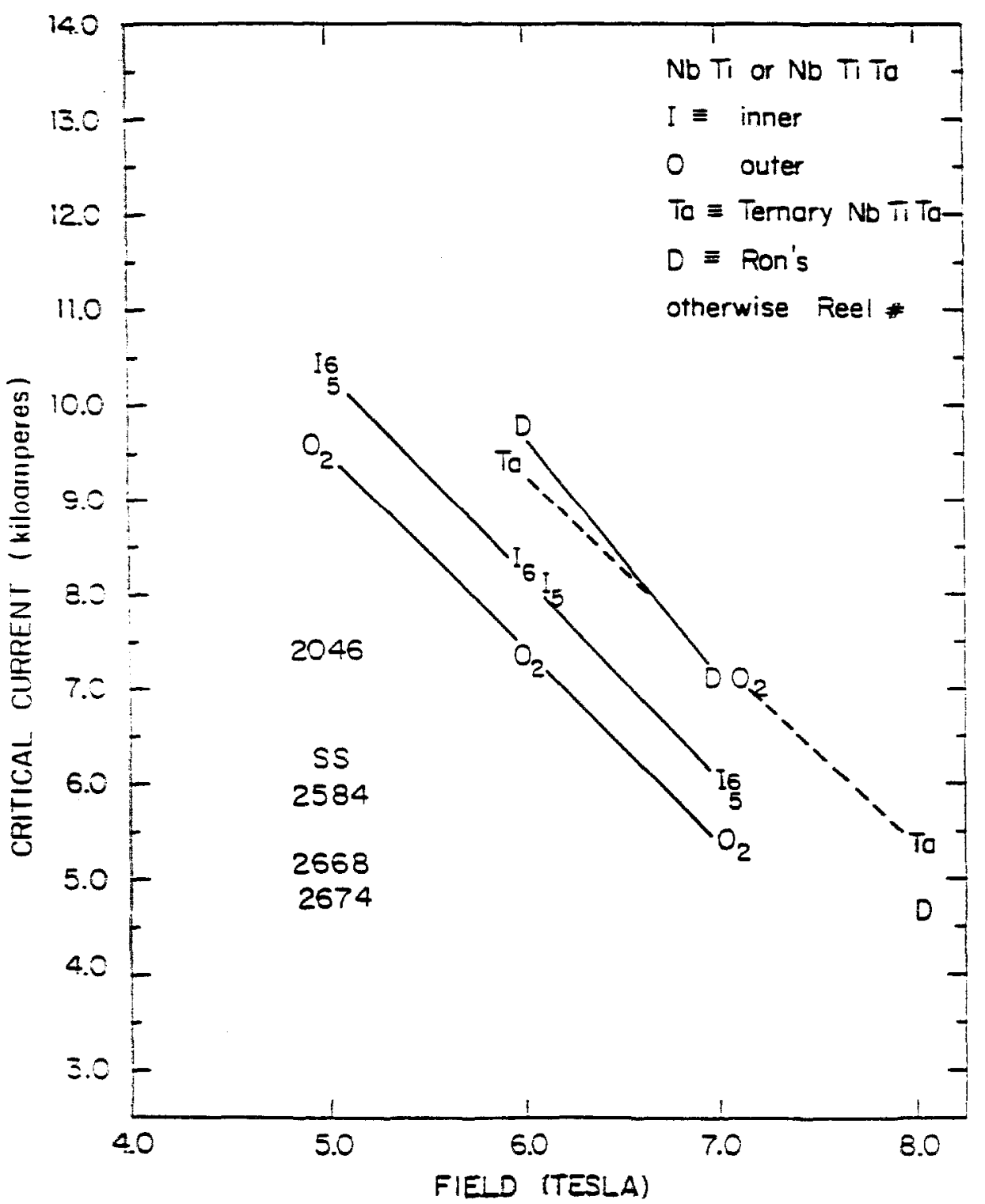

Fig. 5. This graph gives the current at which the effective resistivity of the whole cable is $2+4 \times 10^{-12} \Omega-\mathrm{cm}$ in the perpendicular magnetic field intensity plotted on the " $x$ " axis.

These model magnets are wound dry (no epoxy or fiberglass) or Kapton plus "B" stage epoxy; or Kapton, fiberglass and "B" stage epoxy. See Figure 7. The dry winding technique uses an expanding mandril which is removed once the coil is secured in the aluminium collars which in turn are keyed together.

The illustration in Figure 7 shows a dipole winding which is similar to that of a quadrupole, except the quad collars are pushed from all four sides instead of two. There is also another design variation that is shown (See Figure 8) in this model series, mainly the substitution of a five fold multiplicity of conductors for the 


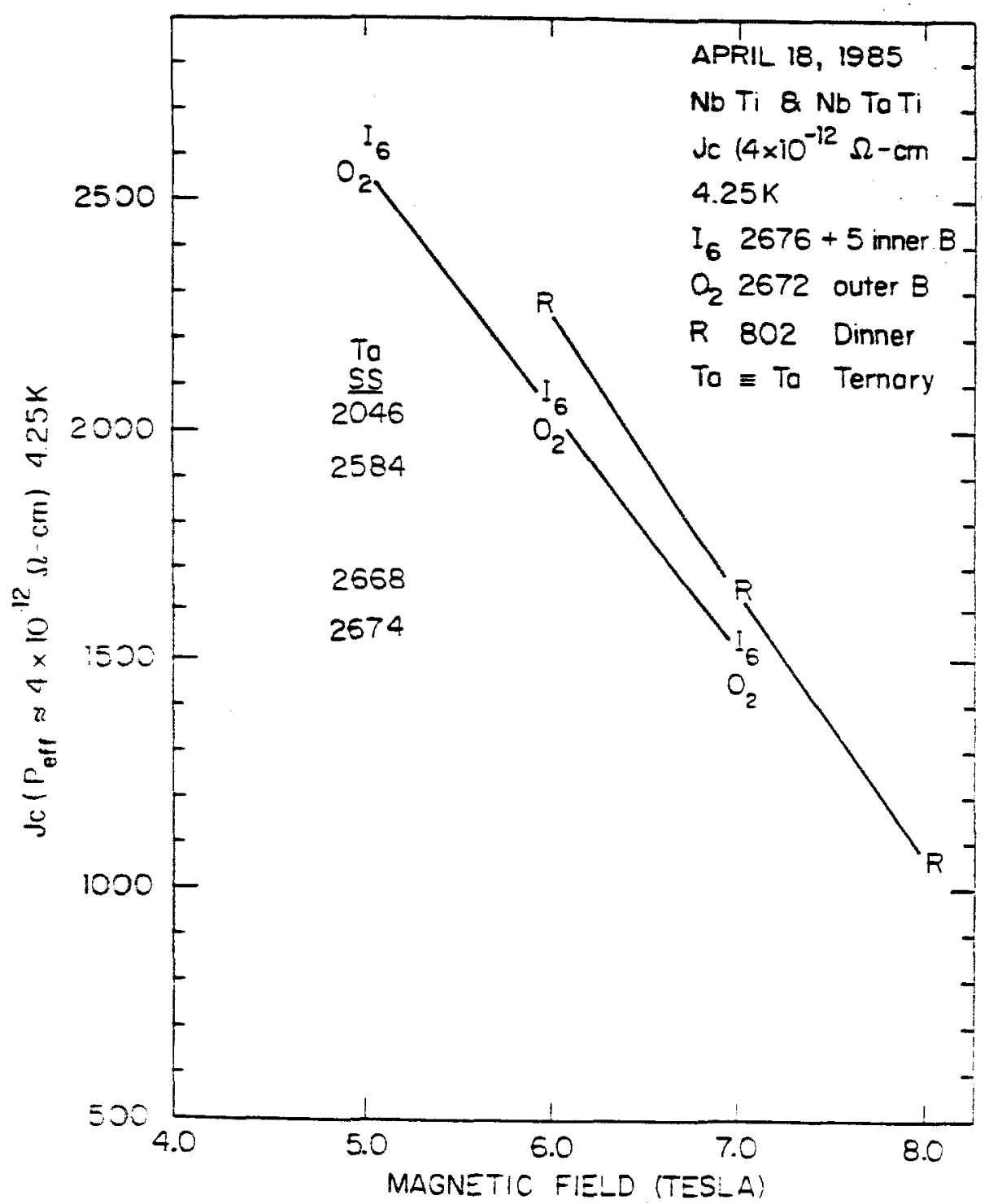

Fig. 6. This graph gives the critical current density of the cable at which it's effective resistivity is $2+4 \times 10^{-12} \Omega-\mathrm{cm}$ in the perpendicular magnetic field intensity plotted on the " $x$ " axis.

single large five kiloampere cable; therefore, reducing the refrigeration load of the current input leads. This will effect $a$ $25 \%$ savings in the estimated refrigeration load if magnet is in it's own cryostat operating d.c.. The filament size for the various quadrupoles are from 8 to $40 \mathrm{microns}$ and copper/NbTi volume ratio is 1.3 to 1.75 . The field quality measured in these prototypes is given in Table III.

A superconducting winding can undergo a premature superconducting to normal transition before it reaches the intersection of the critical surface and the high field load line due to local hot spots caused by a mechanical motion, friction, micro-cracking, flux jumps, etc. This transition is called a "quench". The conductor design usually 
TABLE I

Low B Quad Cable

\begin{tabular}{|c|c|c|c|}
\hline $4.35 \mathrm{~K}$ & & & \\
\hline Best & $7 \mathrm{~T}$ & $5.148 \mathrm{kA}$ & $147.6 \mathrm{kA} / \mathrm{cm}^{2}$ \\
\hline & $8 \mathrm{~T}$ & $3.502 \mathrm{kA}$ & $100.4 \mathrm{kA} / \mathrm{cm}^{2}$ \\
\hline & $9 \mathrm{~T}$ & $1.771 \mathrm{kA}$ & $50.77 \mathrm{kA} / \mathrm{cm}^{2}$ \\
\hline Typical & $6 \mathrm{~T}$ & $5.425 \mathrm{kA}$ & $155.5 \mathrm{kA} / \mathrm{cm}^{2}$ \\
\hline & $7 \mathrm{~T}$ & $4.275 \mathrm{kA}$ & $122.5 \mathrm{kA} / \mathrm{cm}^{2}$ \\
\hline & $8 T$ & $3.100 \mathrm{kA}$ & $88.88 \mathrm{kA} / \mathrm{cm}^{2}$ \\
\hline Later Material & $5 \mathrm{~T}$ & $7.270 \mathrm{kA}$ & $208.4 \mathrm{kA} / \mathrm{cm}^{2}$ \\
\hline & $6 \mathrm{~T}$ & $6.100 \mathrm{kA}$ & $174.9 \mathrm{kA} / \mathrm{cm}^{2}$ \\
\hline & $7 \mathrm{~T}$ & $4.95 \mathrm{kA}$ & $141.9 \mathrm{kA} / \mathrm{cm}^{2}$ \\
\hline & $8 \mathrm{~T}$ & $3.65 \mathrm{kA}$ & $104.6 \mathrm{kA} / \mathrm{cm}^{2}$ \\
\hline & $9 \mathrm{~T}$ & $2.45 \mathrm{kA}$ & $70.24 \mathrm{kA} / \mathrm{cm}^{2}$ \\
\hline & $10 \mathrm{~T}$ & $1.25 \mathrm{kA}$ & $35.84 \mathrm{k} / \mathrm{cm}^{2}$ \\
\hline d $M$ & Tevatron & Cable & \\
\hline & $4 T$ & $6.050 \mathrm{kA}$ & $198.8 \mathrm{kA} / \mathrm{cm}^{2}$ \\
\hline & $5 \mathrm{~T}$ & $5.000 \mathrm{kA}$ & $164.2 \mathrm{kA} / \mathrm{cm}^{2}$ \\
\hline & $6 \mathrm{~T}$ & $4.000 \mathrm{kA}$ & $131.4 \mathrm{kA} / \mathrm{cm}^{2}$ \\
\hline
\end{tabular}

removes the possibility of flux jumps. The preloading on the winding is normally in excess of the magnetic forces, therefore eliminating gross or large scale mechanical motion. In any design, nevertheless, there is still the possibility of micro-cracking, and stick slip frictional heating. Therefore, the current indicated by Q's in Figure 4 are the successive quenches with the "N" standing for the "N"th quench since construction. In general, the windings have a memory as long as they are not mechanically disturbed. In other words, they will operate at the highest or nearly highest field level it has previously attained. This coil memory is not always perfect if the magnet is thermally cycled. A way in which to avoid the thermal cycling complication is to match the thermal expansion and contraction characteristics of the materials used to construct the magnet or at least compensate for differences.

Figure 9 is the same type curve as Figure 4; the windings are identical with the only exception being the substitution of low ' $\beta$ ' quadrupole cable for standard Tevatron cable or the copper volume in SQ1003 (SL1003) is 1.3 instead of 1.75 in SQ1001(SL1001). Note it is a common test procedure to quench (train) the coil at a lower temperature than is needed for operation in order to "stretch" it. This procedure usually minimizes the possibililty for an unexpected quench below the operation current.

The windings SL1001 and SL1003 are compared in Figure 10 and their quench parameters are shown to be very similar when the cable's parameters are considered. This behavior usually means there are no structural limits up to the maximum current and field level attained. The performance design load line plot (similar to Figs. 4 \& 9) for the 5 in 1 conductor quadrupole is shown in Figure 11. 
Table II.

THE 5.0CN APERTURE MAGNT MODEL SERIES

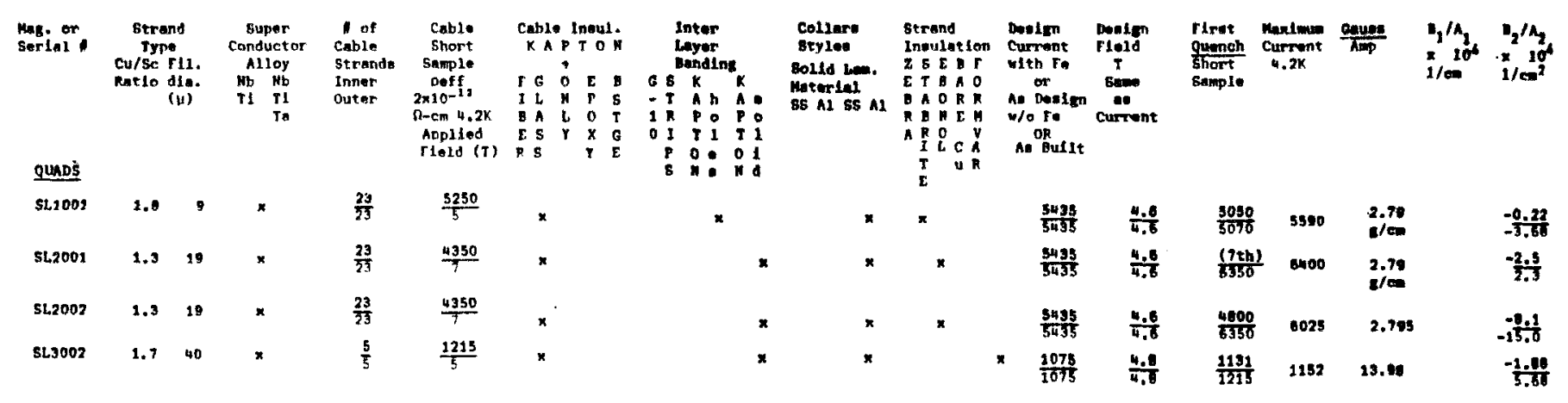


TABLE III

Multipole Moments in Units of $10^{-}$at $1 \mathrm{~cm}$ $(\mathrm{N}=$ Normal; $\mathrm{S}=$ Skew $)$

$\begin{array}{crrrrr} & & \text { SLO01 } & \text { SL003 } & \text { SL007 } & \text { SLO05 } \\ 6 \mathrm{P} & \mathrm{N}-0.22 & -2.51 & -08.1 & -1.88 \\ & \mathrm{~S}-3.68 & -2.34 & -15.0 & 5.68 \\ 8 \mathrm{P} & \mathrm{N} & 0.96 & 1.19 & -04.0 & -0.71 \\ & \mathrm{~S}-7.99 & -5.86 & -00.9 & 0.36 \\ 10 \mathrm{P} & \mathrm{N} & 0.35 & -0.41 & -00 . & 0.73 \\ & \mathrm{~S}-0.33 & -0.39 & -02.5 & 2.74 \\ 12 \mathrm{P} & \mathrm{N} & 7.63 & 1.10 & -03.11 & -3.79 \\ & \mathrm{~S} & 0.11 & -0.07 & 00.04 & 0.27 \\ 14 \mathrm{P} & \mathrm{N}-0.05 & -0.04 & 00.05 & 0.02 \\ & \mathrm{~S} & 0.04 & -0.02 & -00.02 & 0.01\end{array}$

The cable's geometry does not allow current sharing between strands, yet the performance is excellent. The performance of a particular prototype can be shown by plotting the quench current against the number of quenches since the winding was constructed or "quench history." Figure 12 is the quench history for SL007 (SL2002) which is the $5 \mathrm{~cm}$ aperture quadrupole winding utilizing a low copper/NbTi volume cable $(1.3 / 1)$ 2616. As can be seen in the plot, low temperature "stretching" was employed during the training of this winding. The result is that Quench 8 was 500 amperes higher than the earlier $4.2 \mathrm{~K}$ quench currents. Quenches 10 through 15 were increasing ramp rates to measure sensitivity of the quench limit to dI/dt. Figure 13 shows the maximum quench current as a function of ramp rate (dI/dt). These are characteristics of the winding and conductor that must be considered when designing quadrupoles for various applications. The photograph in Figure 14 is that of SL3002, the 5 in 1 conductor quadrupole coil.

The $7.6 \mathrm{~cm}$ Aperture Coil Series

The $7.6 \mathrm{~cm}$ models (quadrupoles) were constructed to see if it would be possible to substitute less expensive materials or less labor intensive assembly procedures for the construction of Tevatron ring magnets. The quadrupole models for this study and their parameters are given in Table IV.

The performance design load line plot (similar to Fig. 4, 9, \& 11) for the $7.6 \mathrm{~cm}$ quadrupole (air core) windings is shown in Figure 15. Due to the experience, knowledge, and technique gained during the construction of the $216(1.68 \mathrm{~m})$ standard quadrupoles, plus several dozen special purpose quadrupoles, the performance of this winding series is well documented and very good as indicated in Figure 15. This performance is typical of the majority of the Tevatron ring quadrupoles.

The photo of the special quadrupole, TH3203F, with a temperature 
TABLE IV

The $7.6 \mathrm{~cm}$ Aperture Magnet Model Sertes

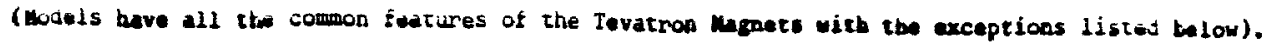

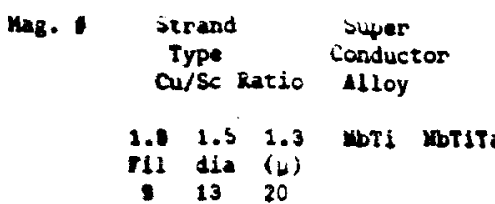



\begin{tabular}{|c|c|c|}
\hline \multicolumn{3}{|c|}{$\begin{array}{l}\text { Inter } \\
\text { Layer } \\
\text { Banting }\end{array}$} \\
\hline & $\mathbf{K}$ & $k$ \\
\hline & $A$ & $A$ \\
\hline R & $P O$ & $\mathbf{P}$ \\
\hline I & $T 1$ & $T$ \\
\hline P & $\dot{i}$ & $0 i$ \\
\hline 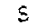 & N S &  \\
\hline
\end{tabular}



With straad 4l Insulation 1ic8 Clfs 2 Insularico E T

B A. E

B $\mathrm{H}$

a $R$

I

x

$\times$

$\mathbf{x}$

reduction $(<4.5 \mathrm{~K})$ heat exchanger in front of the power-correction package Tevatron spoolpiece, TSH398, is shown in Figure 16. This setup was used to verify the improved performance with temperature reduction in a normal horizontal accelerator running mode. A quench summary for the $7.6 \mathrm{~cm}$ series quadrupoles is given in Table $V$.

TABLE V

QUENCH SUMMARY

\begin{tabular}{|c|c|c|c|c|c|c|}
\hline Number & $\begin{array}{l}\text { Critical } \\
\text { Current } \\
\text { Cable }(4.2 \mathrm{~K}) \\
(\mathrm{kA})\end{array}$ & $\begin{array}{l}\text { High } \\
\text { Quench } \\
\text { (kA) } \\
4.2 \mathrm{~K}\end{array}$ & $\begin{array}{l}\text { Quenches } \\
\text { to } 95.7 \%\end{array}$ & $\begin{array}{l}\text { Quenches } \\
99 \%+\end{array}$ & $\begin{array}{l}\text { H1 ghest } \\
\text { Quench } \\
\text { kA } \\
\text { at any } \\
\text { temperature }\end{array}$ & $\begin{array}{l}\Delta I_{Q} \\
\Delta \Delta(d B / d t) \\
0+1600 / \mathrm{sec}\end{array}$ \\
\hline $\begin{array}{l}\text { TSQ2509 } \\
\text { TS225i1 } \\
\text { TSQ2512 } \\
\text { TS: } 32030 \\
\text { (-1Fe) }\end{array}$ & $\begin{array}{l}6.6 \\
5.37 \\
5.37 \\
4.87\end{array}$ & $\begin{array}{l}6.8 \\
5.55 \\
5.50 \\
4.9\end{array}$ & $\begin{array}{l}2 \\
1 \\
1 \\
1\end{array}$ & $\begin{array}{l}3 \\
2 \\
2 \\
2\end{array}$ & $\begin{array}{l}8.6(2.0 K) \\
6.25 \\
6.10 \\
5.5(3.95 K) \\
1.11 \mathrm{~T} / \mathrm{ar}\end{array}$ & $\begin{array}{l}0 \\
0 \\
0 \\
0\end{array}$ \\
\hline
\end{tabular}

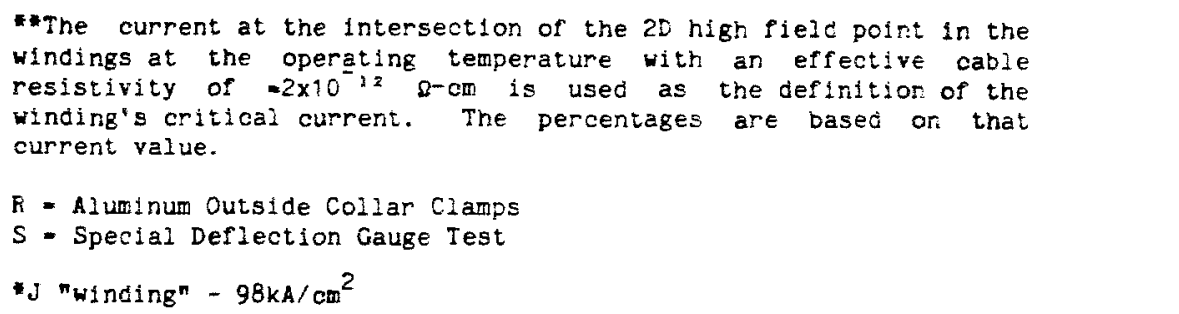

Quadrupole TQ2509F is a "low $B$ " insertion quadrupole prototype collared coil assembly (without the iron shield) that has been tested in atmospheric pressure superfluid helium (2K). The coil exceeded the cable's $\rho_{\text {eff }}=2 \times 10^{-12} \Omega-\mathrm{cm} 4.2 \mathrm{~K}$ current on the third quench. When the coil operated in superfluid liquid helium at $2 K$, it trained to 8.6 kiloamps in seven quenches or a gradient of $1.35 \mathrm{~T} / \mathrm{cm}$. The quench history of TQ2509F is shown in Figure 17. For comparison, the quench history of a standard Tevatron quadrupole is shown in Figure 18. Note: Maximum operating current Tevatron is 




Figure 7(a)

Coil wounc on

Coliapsable mandrel

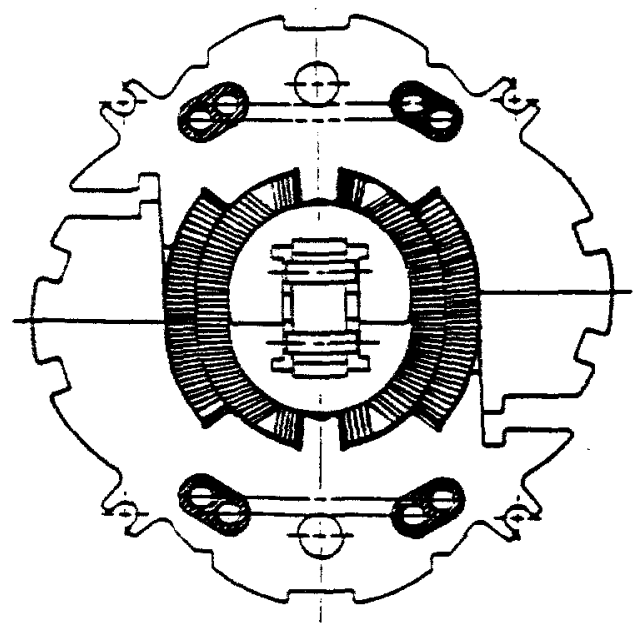

Figure $7(c)$

Coil collared but not preloadec and keyed

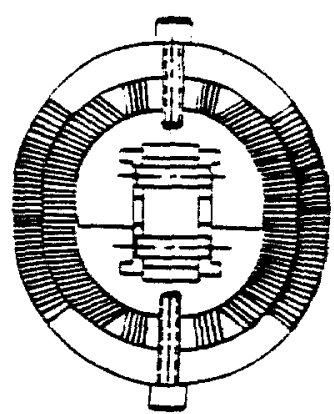

Eigure $7(b)$

Coiz wound Ready for Coliars

Fig. 7. Figures $a \rightarrow d$ are the various steps in a dry wound dipole coil. A similar procedure is used for the quadrupole except all four sides are pushed on.

$4.45 \mathrm{kA}$ at $4.5 \mathrm{~K}$ This corresponds to $0.76 \mathrm{~T} / \mathrm{cm}$ maximum gradient. The longest quadrupoles in the Tevatron are 4.6 meters, but their performance is similar.

The typical quadrupole harmonic co-efficients are given in Table VI. These are mean measurements of most of the Tevatron production. Another feature which is unique to a superconducting winding is the hysteresis in the harmonics due to magnetization of the superconductor itself. This hysteresis shown in the normal 12 pole co-efficient for two different filament sizes and volumes NbTi cables used in Tevatron quadrupoles. 

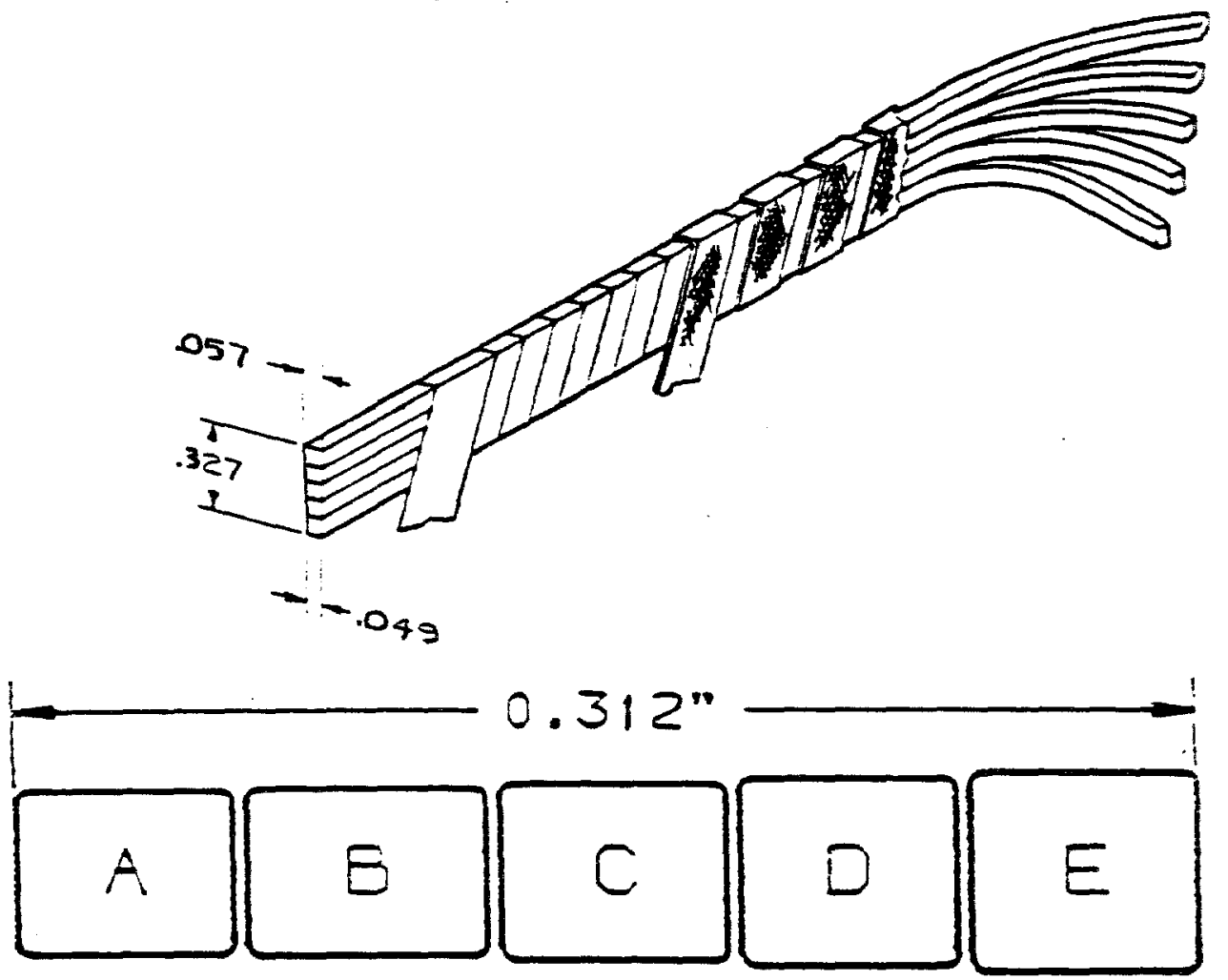

Five In Cre cable Conductor Charactartsetcs

\begin{tabular}{|c|c|c|c|c|c|}
\hline nducsor Type & $\boldsymbol{\lambda}$ & $\mathbf{3}$ & $c$ & - & $\varepsilon$ \\
\hline & $\begin{array}{l}.064 \\
.043\end{array}$ & $\begin{array}{l}.061 \\
.045\end{array}$ & $\begin{array}{l}.059 \\
.047\end{array}$ & $\begin{array}{l}.056 \\
.049\end{array}$ & $\begin{array}{l}.051 \\
.051\end{array}$ \\
\hline AE $5 T$ & 1400 & 1350 & 1290 & 1277 & 1215 \\
\hline
\end{tabular}

Fig. 8. The diagram shows the 5 in 1 conductor substitution geometry. This type of substitution allows the same set of production tooling to make either ring quads or d.c. beam line units with equal ease with only the extra interwire connections adding to the complexity.

TABLE VI

QUADRUPOLE HARMONIC COEFFICIENTS

$\begin{array}{ccc}\text { POLE } & \text { NORMAL } & \text { SKEW } \\ 6 & 33 & 47 \\ 8 & 7.9 & -1.8 \\ 10 & -0.72 & -1.4 \\ 12 & -1.71 & 0.2 \\ 14 & .01 & .07 \\ 18 & -.00 & -.01 \\ 20 & -.010 & .01 \\ 24 & -.002 & .002 \\ 28 & .007 & -.002\end{array}$




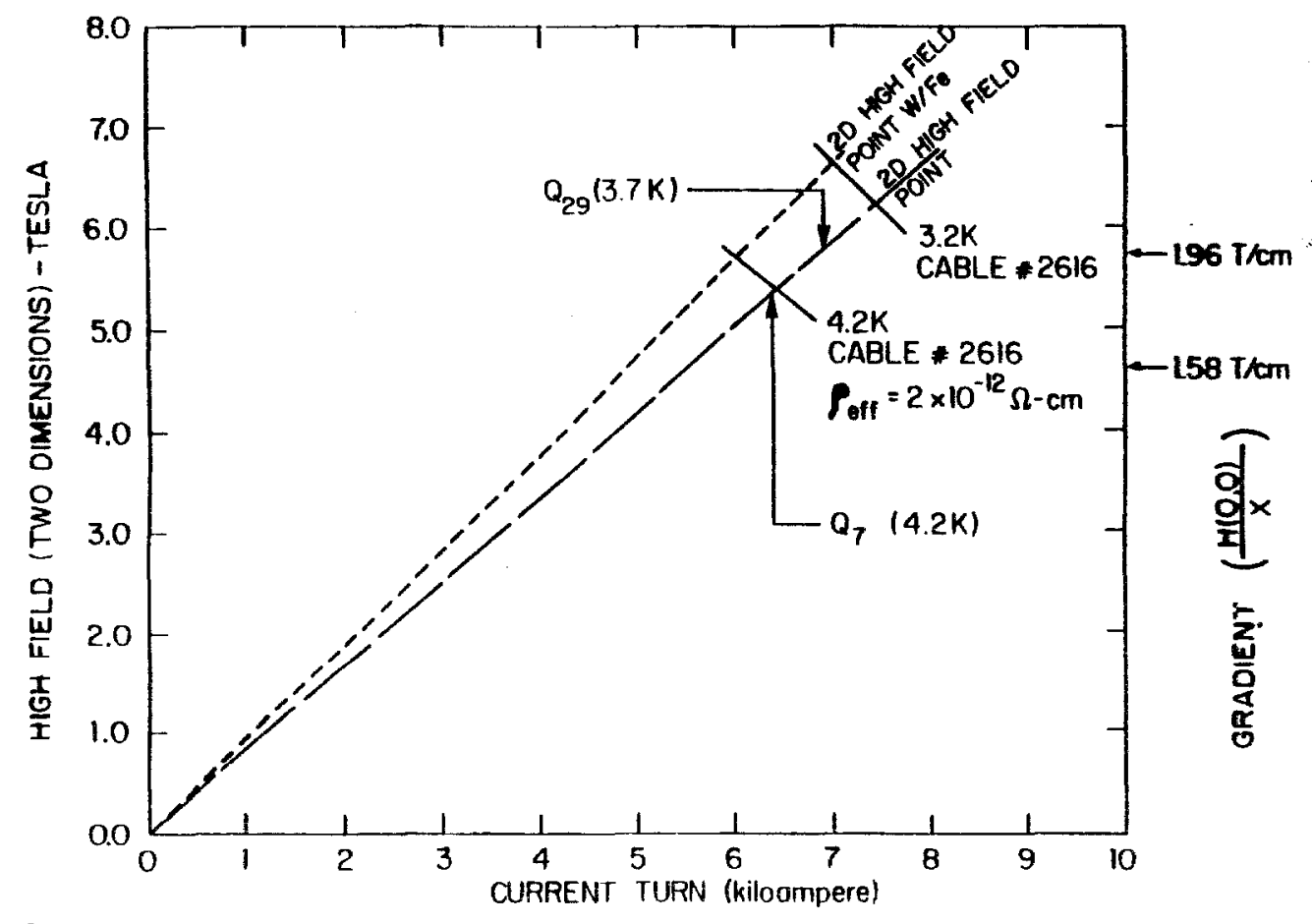

Fig. 9. This is a plot of the peak magnetic field or the gradient on the axis of the coil as a function of the current. The " $Q_{N}(T)$ " stands for the "N"th superconducting to normal transition undergone by the coil, SQ1003, since it was wound. This type of plot will be referred to as a performance curve. "T" stands for the bath temperature.

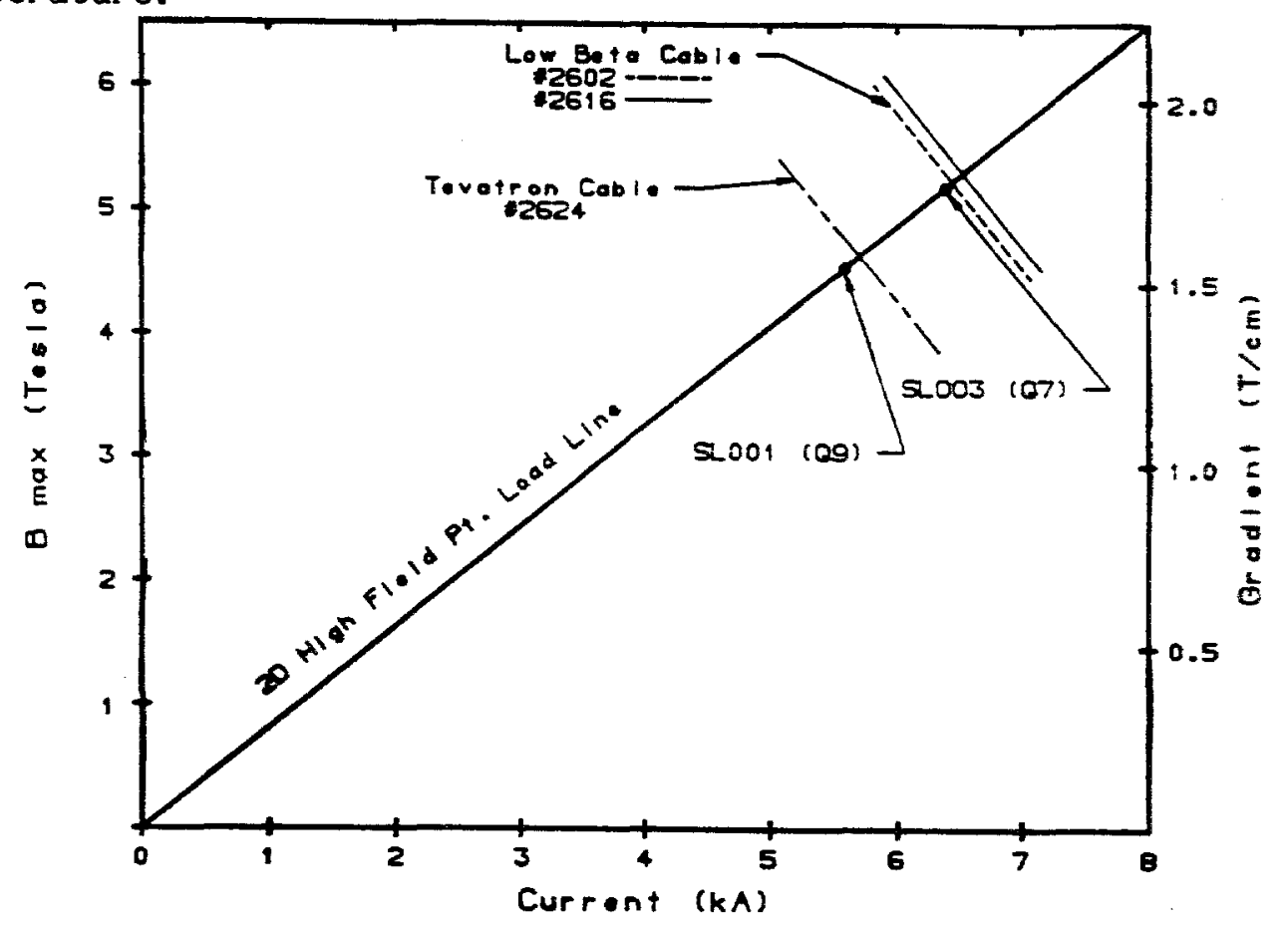

Fig. 10. This is a performance load line comparison of two different quadrupoles with $5 \mathrm{~cm}$ apertures. 


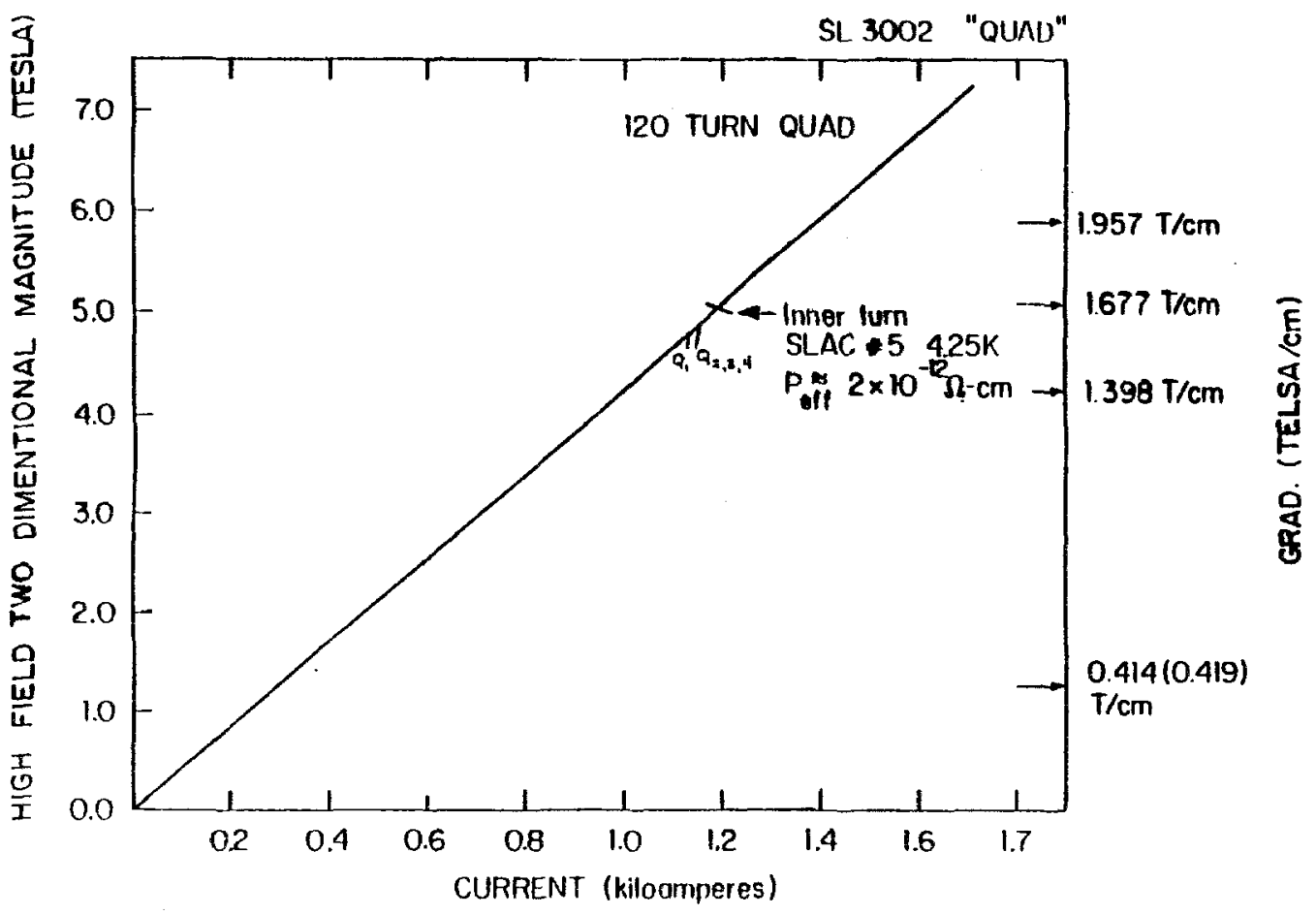
Fig. 11. This is a performance plot for the 5 in 1 conductor magnet
"SL3002."



Fig. 12. This is the quench history for, SL2002, a $5.0 \mathrm{~cm}$ aperture high gradient quadrupole. 




Fig. 13. This figure illustrates the ramp rate sensitivity of the maximum quench current for two different $5 \mathrm{~cm}$ aperture quadrupoles.

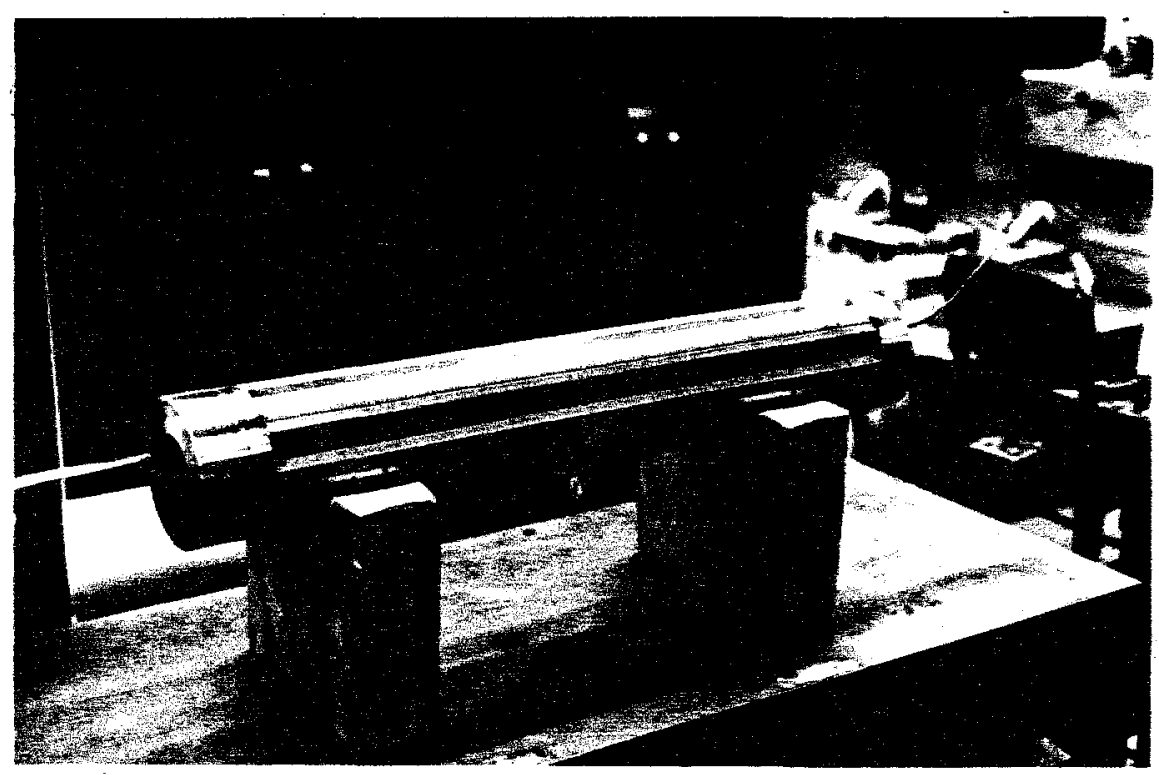

Fig. 14. This is a photograph of a high gradient $5 \mathrm{~cm}$ aperture quadrupole proposed for the final focus of SLC at SLAC. 




Fig. 15. This is a performance plot for Tevatron style collared coil assembly. " $\mathrm{Q}_{N}(T){ }_{N}$, stands for the "N"th superconducting to normal transition undergone by the TQ32N' collared coil assembly since its construction. The quench occurred in a helium bath temperature of "T".

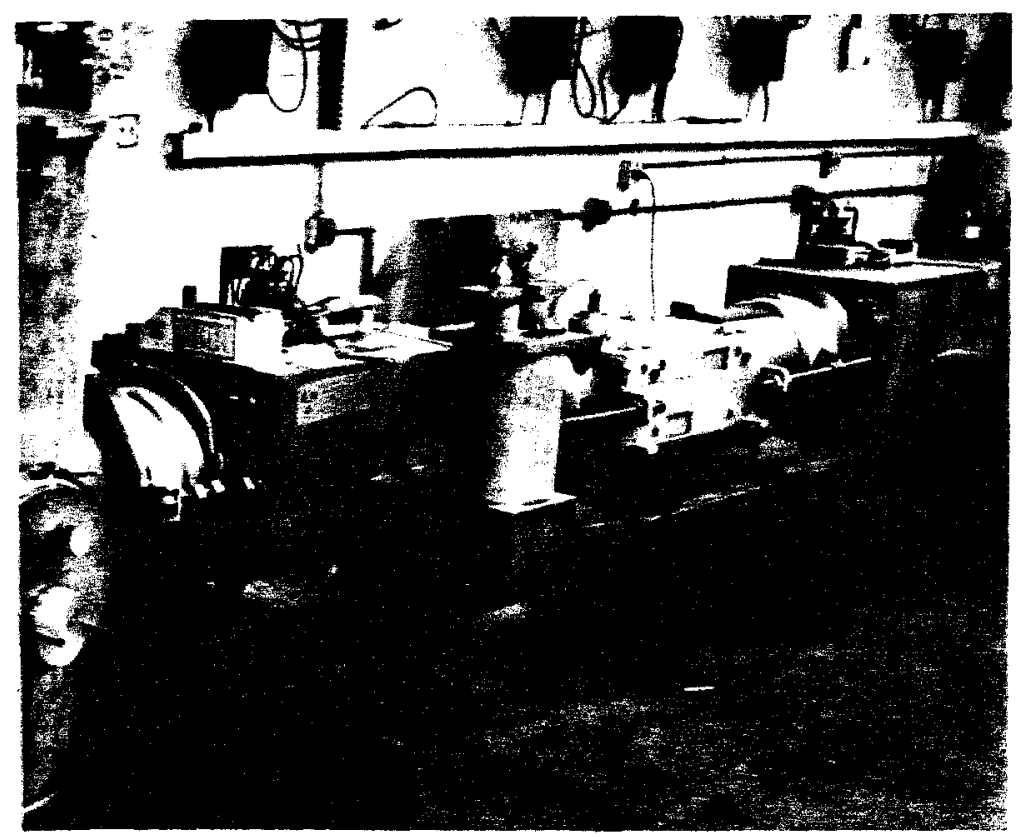

Fig. 16. A photograph of TH3203F quadrupole being tested in a horizontal "Tevatron Type" string with a special heat exchanger (for temperatures $(4.5 \mathrm{~K}$ ) installed in front of the power correction spool, TSH398. 




Fig. 17. This is the quench history for a "low $\beta$ " insertion quadrupole collared coil assembly (w/O Fe) "TQ3209F."

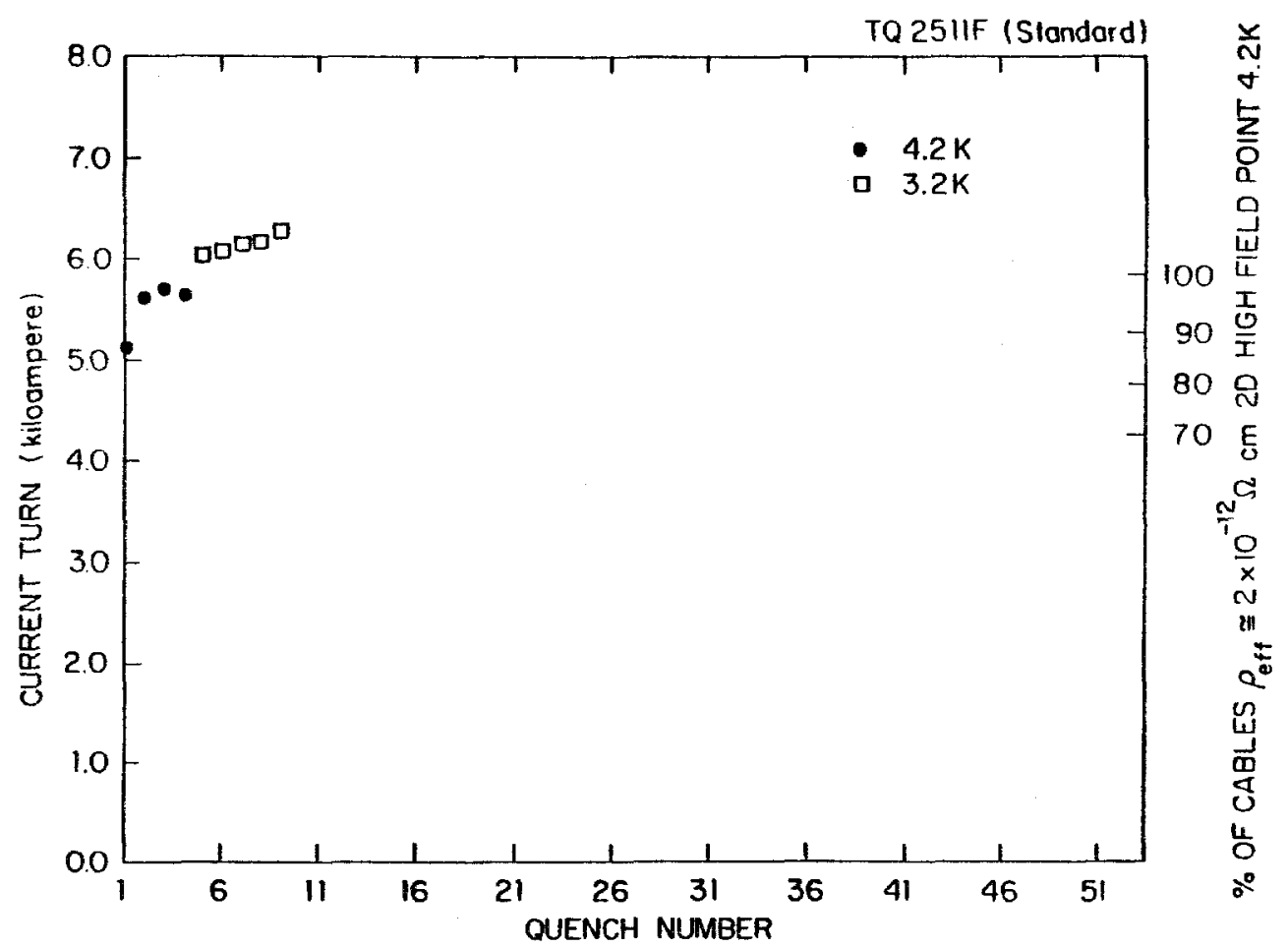

Fig. 18. This is the quench history for a standard ring Tevatron quadrupole collared coil assembly (w/o Fe). Note at $4.2 \mathrm{~K}$ only one "training" (premature quench before $100 \%$ is reached) quench. 
quadrupole and a photograph of a collared coil assembly cross section.

\subsection{Aperture Coil Series}

This series of quadrupoles was constructed at Brookhaven as prototype for the then proposed $p, p$ storage ring accelerator "ISABELLE". The interesting design feature of these coils is that they utilize "close in" cold iron shields, and are therefore driven into partial saturation before the operational field is reached. The winding configuration of a quadrant is shown in Figure 1. A photograph of a standard $12.1 \mathrm{~cm}$ aperture "ISABELLE" quadrupole is shown in Figure 21. The quench performance is given in Table VII for two $12.1 \mathrm{~cm}$ aperture quadrupoles.

Tabie VII

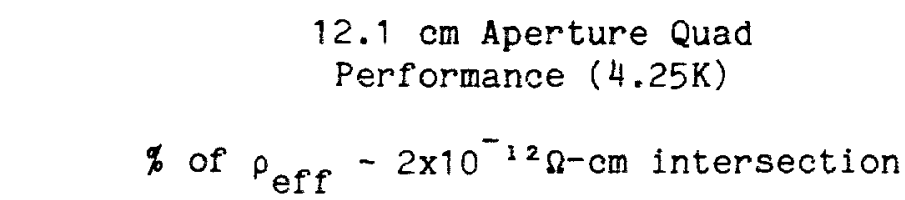

$\begin{array}{lll}\text { 1st } & \text { Highest } & \text { Maximum } \\ \text { Quench } & \text { Quench } & \text { Gradient }\end{array}$

$\begin{array}{llll}\text { Quad I } & 67 & 96 & 0.71 \mathrm{~T} / \mathrm{cm} \\ \text { Quad II } & 66 & 94 & 0.90 \mathrm{~T} / \mathrm{cm}\end{array}$

The effects of iron saturation are shown in Figures 22 and 23 . The iron is brought as close to the winding as possible electricaliy and therefore contributes a large fraction of the field produced, approximately $1.5 \mathrm{~T}$ of the 4.0 tesla peak field. The saturation of the cold iron results in a $3.2 \%$ drop in the gradient produced per ampere and is shown in Figure 22. The saturation of the iron or the distortion of the iron contribution is primarily seen in the 12 pole term and is shown in Figure 23 and can in fact be the dominate term. Normally the winding (as was done in this case) is designed such that at the operating field the 12 pole term is near zero. Therefore correction of the 12 pole requires minimal ampere-turns. The harmonic content of Quad I is given in Table VIII.

Table VIII Magnetic Measurements

\begin{tabular}{|c|c|c|c|c|c|c|}
\hline $\begin{array}{c}I \\
(\mathrm{~A})\end{array}$ & $\begin{array}{c}2 \theta \\
(G / \mathrm{cm} A)\end{array}$ & $\begin{array}{c}3 \theta \\
\left(\mathrm{G} / \mathrm{cm}^{2} \mathrm{~A}\right) \\
\times 10^{-}\end{array}$ & $\begin{array}{c}4 \theta \\
\left(\mathrm{G} / \mathrm{cm}^{3} \mathrm{~A}\right) \\
\times 10^{-5}\end{array}$ & $\begin{array}{c}5 \theta \\
\left(\mathrm{G} / \mathrm{cm}^{4} \mathrm{~A}\right) \\
\times 10^{-6}\end{array}$ & $\begin{array}{c}6 \theta \\
\left(\mathrm{G} / \mathrm{cm}^{5} \mathrm{~A}\right) \\
\times 10^{-5}\end{array}$ & $\begin{array}{c}100 \\
\left(\mathrm{G} / \mathrm{cm}^{\mathrm{9}} \mathrm{A}\right) \\
\times 10^{-9} \\
\end{array}$ \\
\hline $\begin{array}{l}1000 \\
2000 \\
3000 \\
4000\end{array}$ & $\begin{array}{l}1.59 \\
1.59 \\
1.58 \\
1.55\end{array}$ & $\begin{array}{l}1.4 \\
1.4 \\
1.2 \\
1.0\end{array}$ & $\begin{array}{l}4.0 \\
4.0 \\
3.6 \\
3.1\end{array}$ & $\begin{array}{l}5.6 \\
5.6 \\
5.1 \\
4.1\end{array}$ & $\begin{array}{l}-1.11 \\
-1.04 \\
-0.74 \\
+0.03\end{array}$ & $\begin{array}{l}3.5 \\
3.4 \\
3.6 \\
3.3\end{array}$ \\
\hline
\end{tabular}




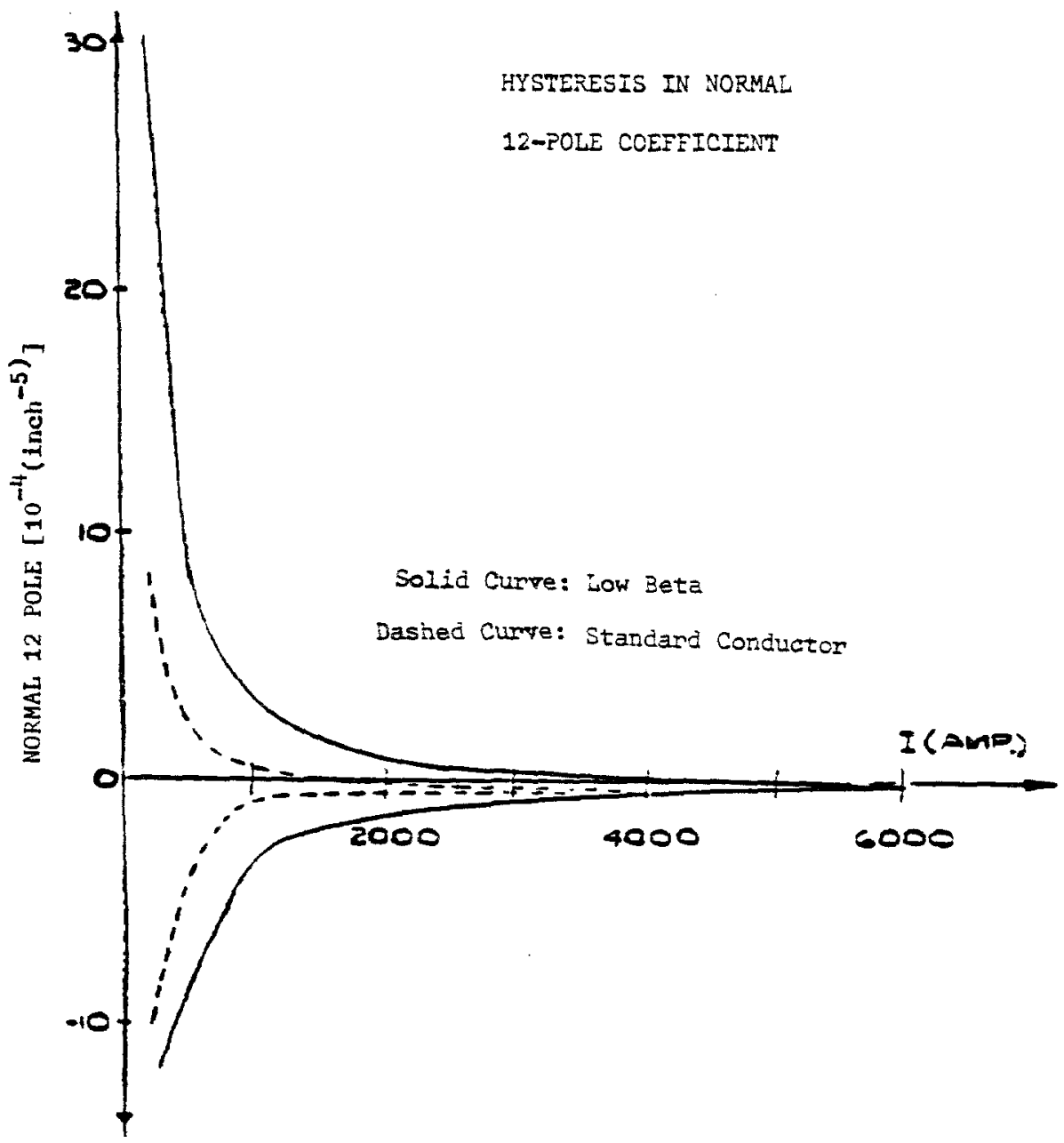

Fig.19. Magnetization hysteresis in the normal 12 pole moments versus current is shown. The dashed curve are data from several standard Tevatron quadrupoles, 2050-8.5 micron diameter filaments of NbTi in a copper matrix strand $1.8 / 1 \mathrm{Cu} / \mathrm{NbTi}$ volume, 23 strands of $0.681 \mathrm{~mm}$ diameter NbTi/Cu composite made into a cable which had an effective resistivity of $2 \times 10^{-12} \Omega-\mathrm{cm}$ for a perpendicular field of $5 \mathrm{~T}$ at a temperature of $4.2 \mathrm{~K}$ measured with the wide side of the cable perpendicular to the magnetic field when carrying 5050 amperes. The solid curve is that of a "low $\beta$ " quad which was based on a conductor composed of 500-20 micron diameter NbTi filaments and a copper/NbTi volume ratio of $1.3 / 1$ and carried 6750 amperes under the conditions listed above.

The "low $B$ " insertion quadrupoles cables have $20 \mu$ NbTi filaments and a copper/NbTi volume ratio of $1.3 / 1$, therefore theoretically the width of the two hystersis curves should differ by $(2.8 / 2.3) \times(20 / 8)$ $=3.04$ if the current densities at a given field are similar. Actually the larger filament material had $\approx 25 \%$ higher current density or this results in a factor of 4 . The widths ratio appears to be $50 \%$ larger than this simple extrapolated estimate.

Figure 20 shows the cross section of a warm iron Tevatron 




Fig. 20. Tevatron Quadrupole Cross Section, the aperture is $7.6 \mathrm{~cm}$ in diameter. 


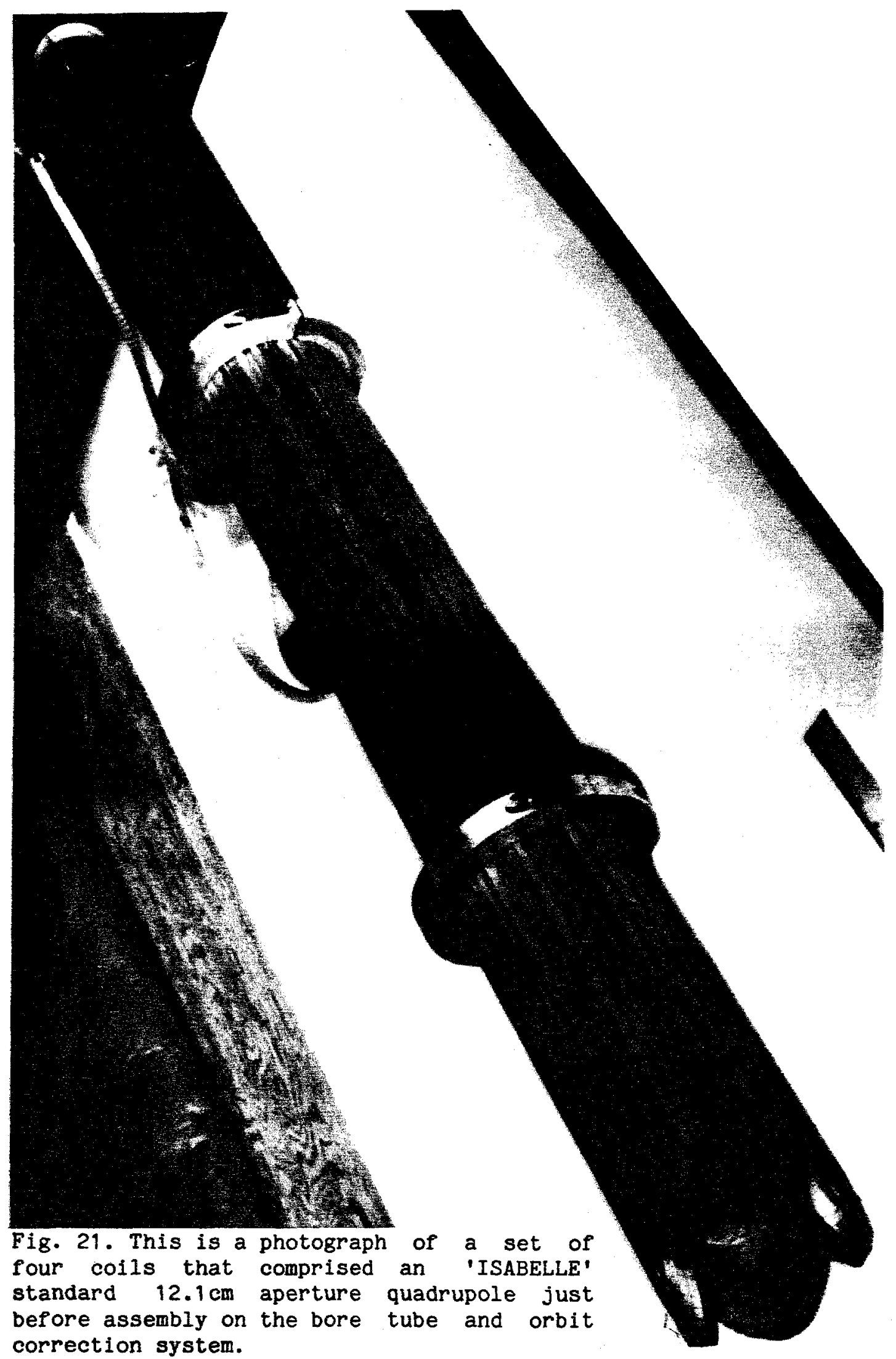






Fig. 22. The plot of the transfer function with respect to the magnet current clearly shows the effects of the "close in" cold iron shield saturating above 2400 amperes for a $12.1 \mathrm{~cm}$ aperture quadrupole with the geometry shown in Figure 1.

\section{Computer Codes To Aid In Design Calculations}

There are several computer codes around which can be used to design the various quadrupoles that might be needed. A few examples are:

1. Mag-Field--A code written for infinite $\mu$ iron with 


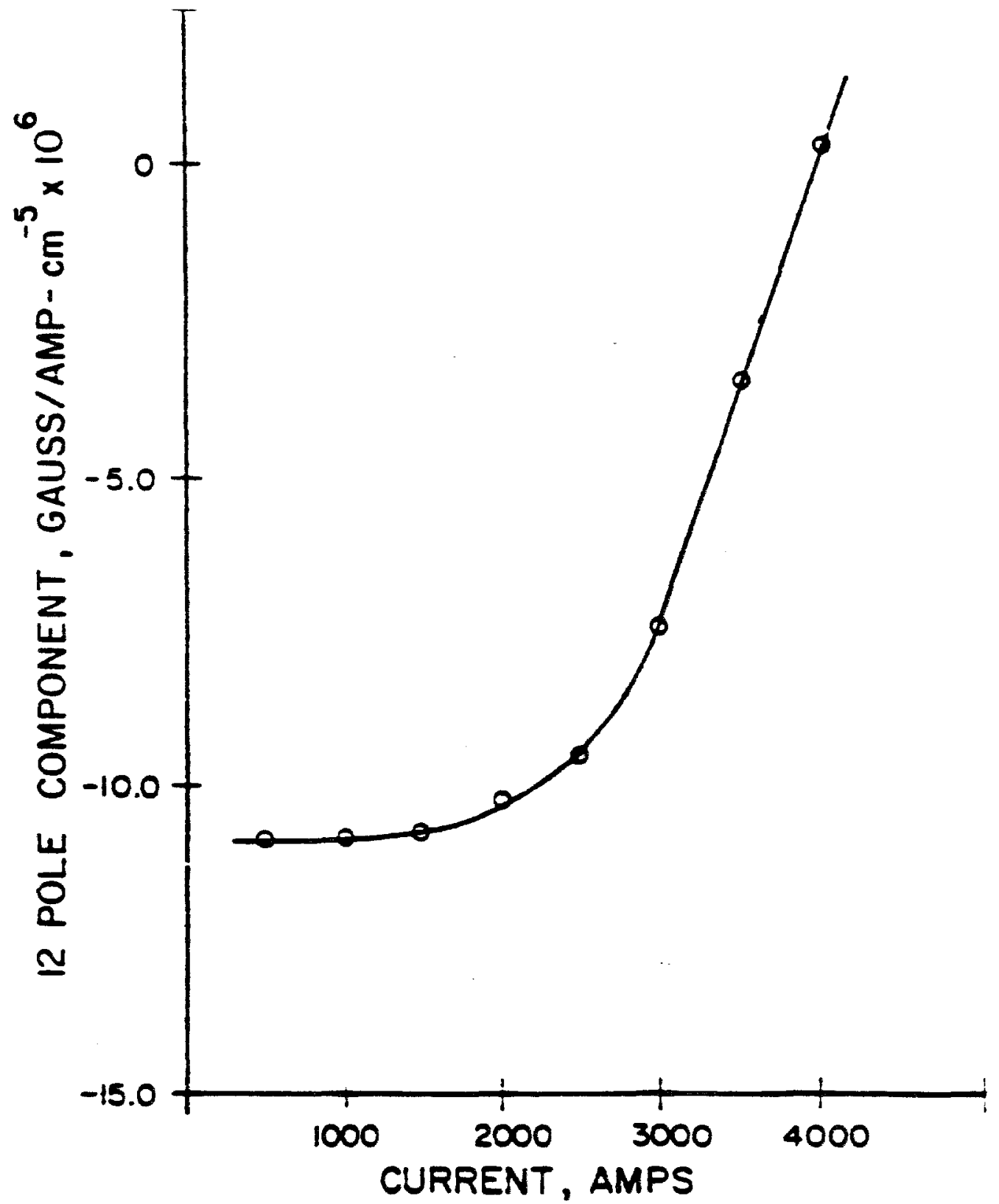

Fig. 23. The effects of iron saturation are clearly evident above 2000 amperes in the plot of the duodecapole as a function of magnet current for the $12.1 \mathrm{~cm}$ aperture quadrupole with the geometry shown in Figure 1.

cylindrical geometry. An analytical code written by G. Morgan, BNL.

2. Mag-Map--A code for calculating solenoidal fields that then can be added to Mag-Field. Example: a detector type device and focus arrangement. 
3. GFUN2D\&3D--An interactive real iron graphics multipurpose code developed by $w$. Trowbridge and Associates at Rutherford Lab.

4. TOSCA 3D--An interactive real iron graphics code. Faster than 3 and reported to be more accurate. Developed by W. Trowbridge and J. Simpkin, etc., at Rutherford Labs.

5. There are also other codes such as PASCAL, TRIM, LINDA, etc.

Design Possibilities For Quadrupoles by 1987

A summary of quadrupole performance of those already in use starting with the older designs and then the most recent is done. The older ISABELLE and TEVATRON style quadrupoles are 0.53 and $0.76 \mathrm{~T} / \mathrm{cm}$ which would have scaled to $1.28 \mathrm{~T} / \mathrm{cm}$ for $5 \mathrm{~cm}$. The modern 184 conductor, but similar in design to the Tevatron, the high gradient $5 \mathrm{~cm}$ aperture quadrupoles for the SLAC final focus have a design gradient of $1.5 \mathrm{~T} / \mathrm{cm}$ for SLC. The two layers of "Rutherford" style cable are easily attaining gradients of $1.6 \mathrm{~T} / \mathrm{cm}$ for an air core version. If the additional 25\% increase in current density is taken into account, then a quadrupole with the general Tevatron features i.e., 2 layer winding based on a "Rutherford" style cable wound into Cos 20 current sheets and modern conductor $5 / 85$, a gradient of $1.75 \mathrm{~T} / \mathrm{cm}$ could be conservatively designed, built, and obtained for a $5 \mathrm{~cm}$ aperture at $4.25 \mathrm{~K}$. The projected numbers for 1987 might reasonably considered to be $\mathrm{J}$ (NbTi) $=2700 \mathrm{~A} / \mathrm{mm}^{2}(5 \mathrm{~T}, 4.25 \mathrm{~K}) \rho \rho_{\mathrm{f}}=2 \times 10^{-12} \Omega-\mathrm{cm}$ in cabled form. Cu/NETi Ratio for a Quad with a small $\leq 7.6 \mathrm{~cm}$ aperture would be in the range of 1.5-1.3 Cu/NbTi and for larger apertures a ratio of $1.4 / 1+\mathrm{Cu} / \mathrm{NbT} i$ which would result in

$J($ cable total area $)=1100 \mathrm{~h} / \mathrm{mm}^{2} 5 \mathrm{~T}, 4.25 \mathrm{~K}$ at $\rho_{\text {eff }}=2 \times 10^{12} \Omega-\mathrm{cm}$.

\section{Typical Apparatus Used For Superconducting Quad Testing}

Typical Magnet conductors used in recent accelerator magnet prototypes are shown in a photograph shown in Figure 24.

The photograph in Figure 25 of the ambient pressure superfluid test fixture which fits into the aperture of a $10 \mathrm{~T}$ solenoid and is used to test magnet cables up to $14 \mathrm{KA}$ to fields as intense as $11 \mathrm{~T}$. A photograph of the vertical $\mathrm{rig}$ for testing model magnet prototypes ( $4.2 \mathrm{~K} \rightarrow 3 \mathrm{~K}$ range) up to $14 \mathrm{KA}$ is shown in Figure 26. Quadrupole TQ2509F is shown mounted in a magnet cryostat fixture for ambient pressure superfluid helium operation with a maximum current capacity of $14 \mathrm{KA}$ and minimum temperature of $1.6 \mathrm{~K}$, in Figure 27.

The standard prototype testing procedure used in the Fermi one meter model Magnet Testing and Development Lab \#2 is given in Appendix I. 


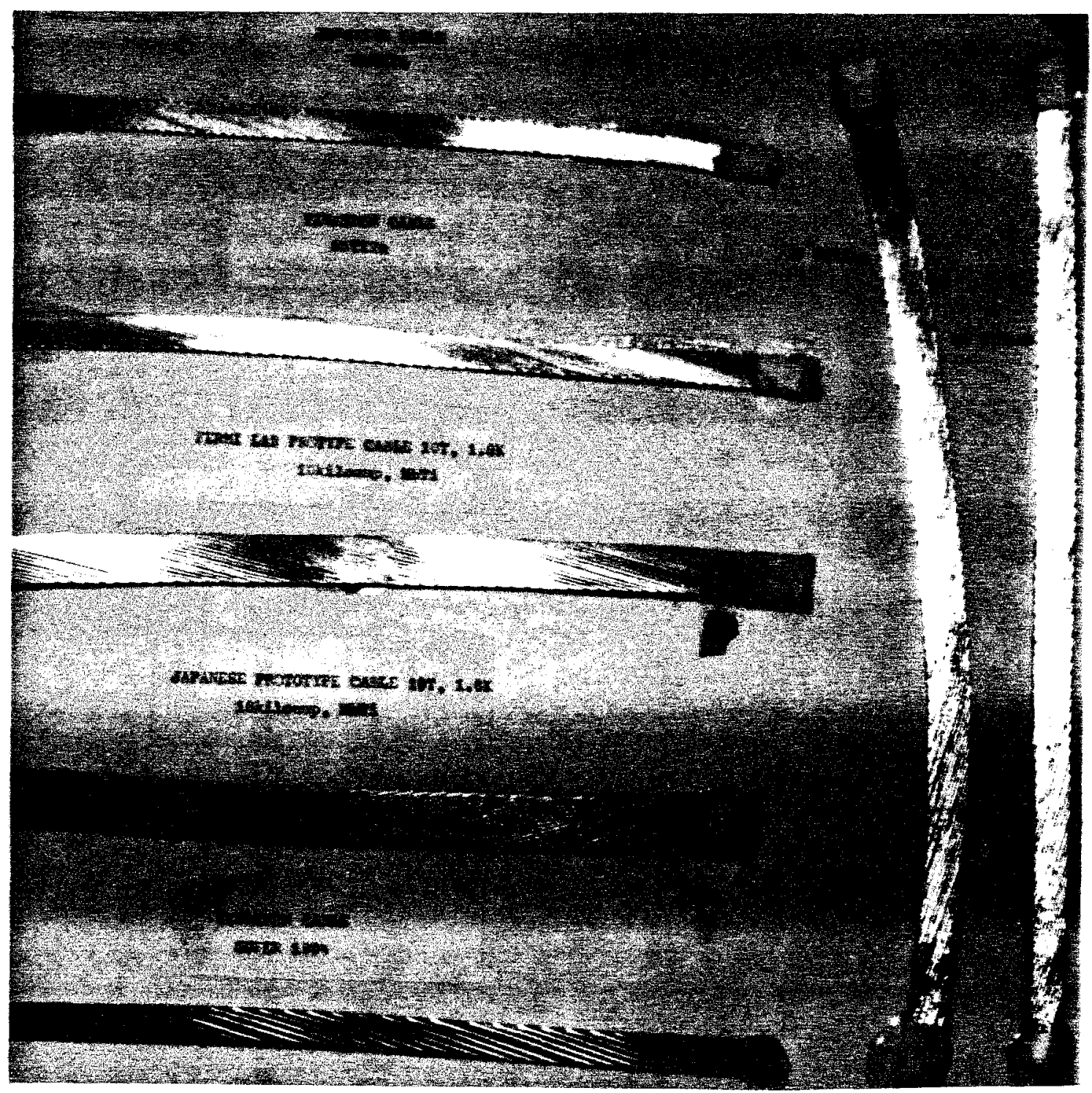

Fig. 24. This is a photograph of several 'Rutherford' style cables that are suitable for fabricating quadrupoles. The high current and low temperature cables, some of which are ternaries, are particularly useful if peak winding fields are on the order of 10T. The scale can be estimated in that the top two and bottom cables are standard Tevatron size which are $0.769 \mathrm{~cm}$ wide. The cables on the right are modern Design "Super Super Collider" SSC prototypes made from $30.5 \mathrm{~cm}$ diameter billets. Their current density as a cable (for filaments only) was a $2650 \mathrm{~A} / \mathrm{mm}^{2}$ for an effective resistivity of $2 \times 10^{-12} \Omega-\mathrm{cm}$ at $5.0 \mathrm{~T}$ and $4.25 \mathrm{~K}$. 


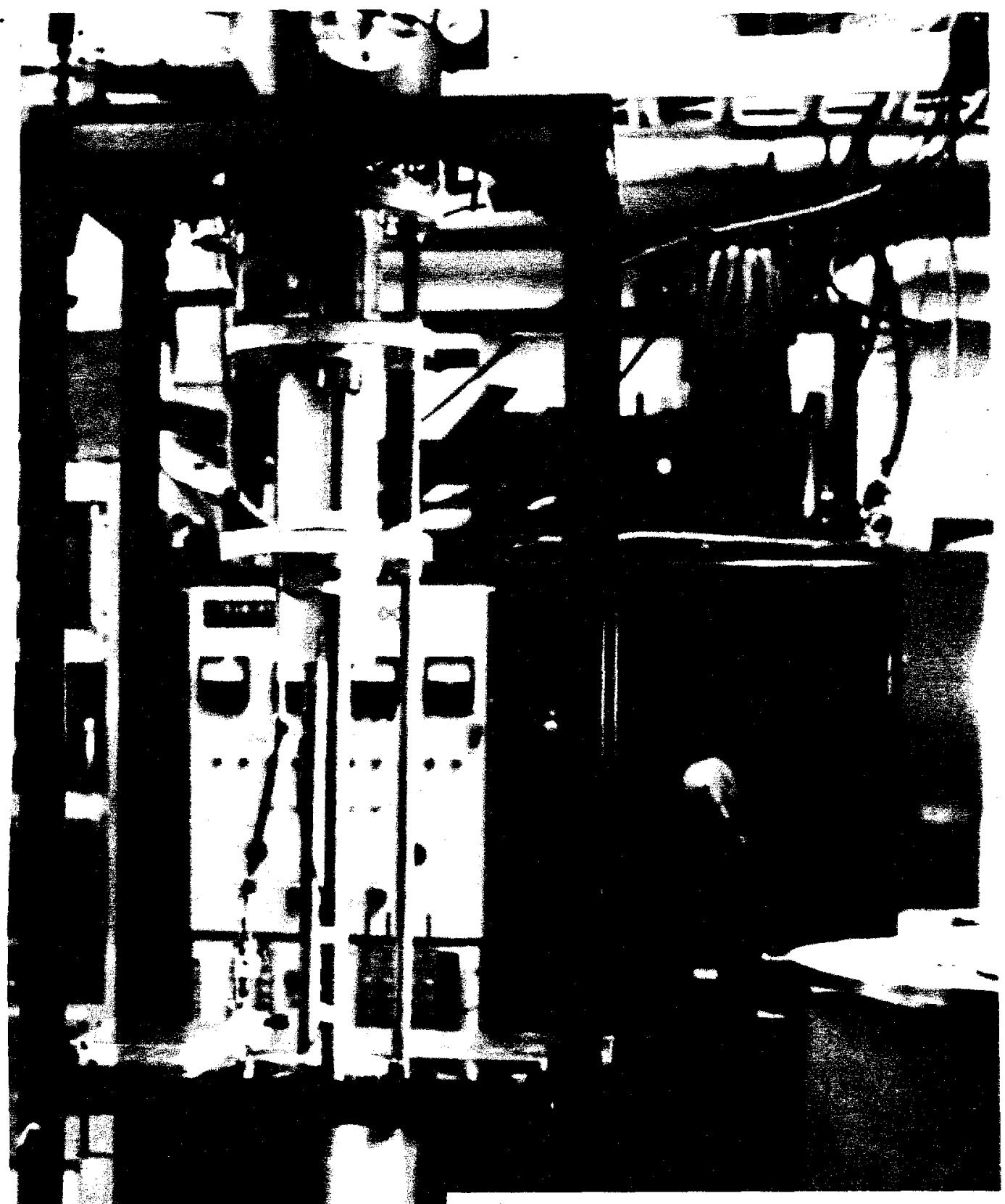

Fig. 25. This is a photograph of a test fixture which was designed by $M$. Wake of KEK as a part of a 10T dipole development of the KEK - FNAL collaboration program. This fixture fits into the bore of a $10 \mathrm{~T}$ solenold and is capable of measuring sample currents up to 14 kiloamperes at temperatures as low as $1.6 \mathrm{~K}$ at ambient pressure. The critical surfaces for the high current low temperature $(\angle 3 \mathrm{~K})$ cables are normally measured in this fixture (i.e. NbTiTa). 


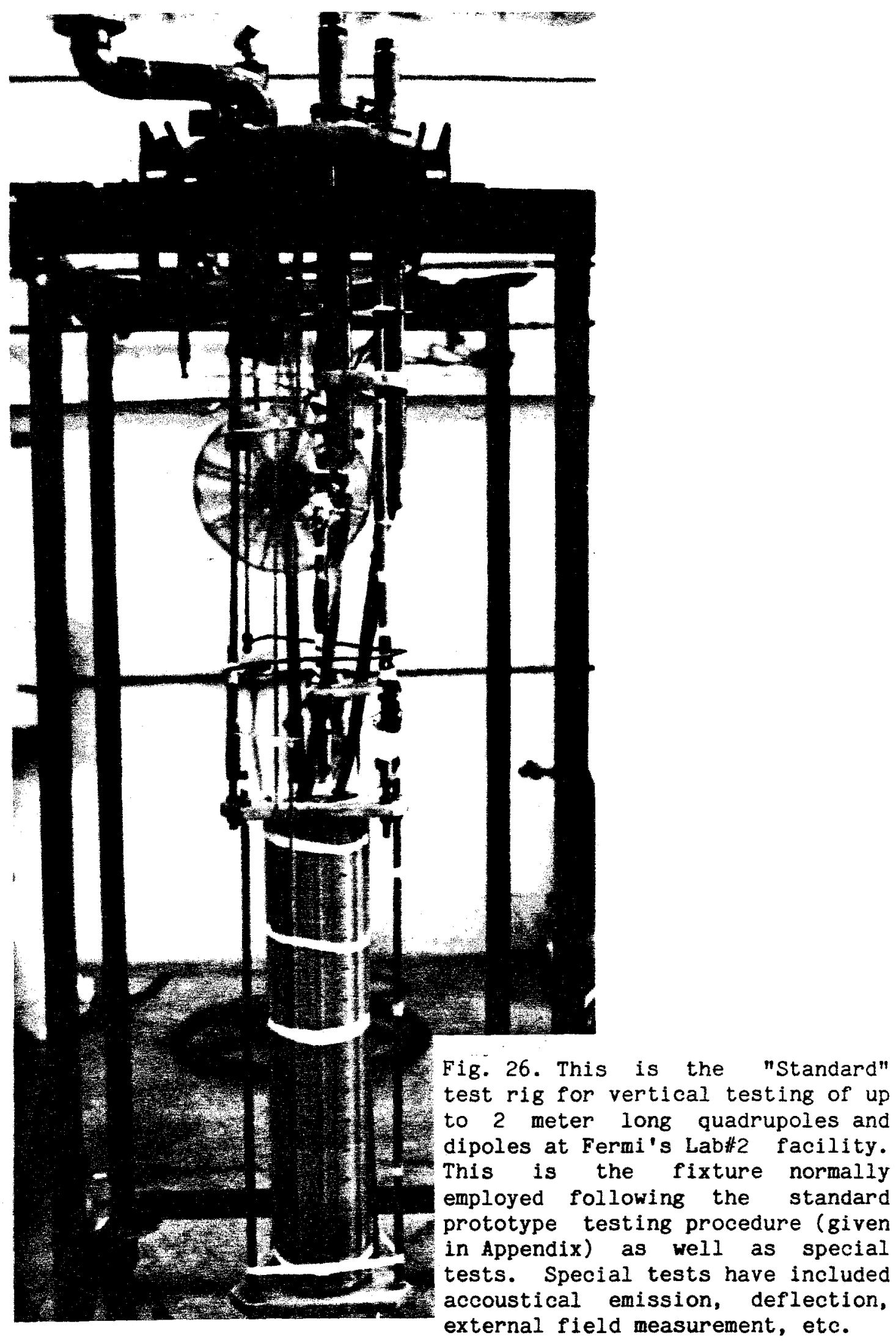





Fig. 27. These two photographs show a magnet mounted in the low temperature ambient pressure fixture on the right and with the fixture totally assembled and ready to be lifted into the dewar to be run on the left. The fixture can take up to a 1 meter model (with new outside jacket possibly to two meters) and has a current carrying capacity of 12 kiloamperes and can keep the winding at one atmosphere pressure with a minimum bath temperature of $1.6 \mathrm{~K}$.

Acknowledgements. As is usual in a paper of this type a majority of the work presented is not that of the author, therefore, the author would like to give recognition to the following people for the $5 \mathrm{~cm}$ aperature work from Fermilab. B.C. Brown, G. Bowden, J. Carson, D. Edwards, N. Engler, H.E. Fisk, J. Ferrie, J. Gonczy, D.A. Gross, 
R. Hanft, J. Hoffman, K. Koepke, M. Kuchnir, P. Leith, R.A. Lundy, T. Mann, P.M. Mantsch, F. Markley, P. Mazur, T. Nicol, R. Niemann, A. Oleck, R. Powers, R. Remsbottom, C. Rode, S. Snowdon, E.E. Schmidt, J. Voss. The workers involved in the $7.6 \mathrm{~cm}$ aperture work in addition to those above are W.E. Cooper, D.A. Gross, M. Johnson, G. Kalbfleisch, J. O'Meara, H. Pfeffer, R. Rajendran, F. Turkot and A. Tollestrup. The $12 \mathrm{~cm}$ aperture quadrupole magnet development which the author was involved in at Brookhaven National Lab was lead by W.S. Sampson and the other valuable members of the team were K.E. Robins, S. Kiss, P.F. Dahl, and Frank Abatello.

\section{References:}

1. R.A. Lundy, B.C. Brown, J.A. Carson, H.E. Fisk, R.H. Hanft, P.M. Mantsch, A.D. McInturff, R.M. Remsbottom, and R.A. Erickson, High Gradient Superconducting Quadrupoles, 1985 Particle Accelerator Conference, Vancover, B.C. May 1985.

2. W.E. Cooper, H.E. Fisk, D.A. Gross, R.A. Lundy, E.E. Schmidt, and F. Turkot, IEEE Trans. On Magn., Vol Mag-19, No. 3, p. 1372, May 1983.

3. W.B. Sampson, K.E. Robins, S. Kiss, P.F. Dahl and A.D. McInturff, IEEE Trans. on Nuclear Science, Vol. NS-24, No. 3, p. 1296-1298, June 1977.

4. D.C. Larbalestier, A.W. West, W. Starch, W. Warnes, P. Lee, W.K. McDonald, P.O.'Reary, K. Hemachalam, B. Zeitlin, R. Scanlan and C. Taylor, IEEE Trans. On Magnetics MAC 21, 269 (Mar 1985). 
APPENDIX I

MAGNET TEST PROCEDORE

I. WARM ELECTRICAL CHECK AND HIGH POT.

II. AFTER MAGNET IS FULL OF LIQUID HELIUM:

A. BALANCE SAFETY CIRCUITS AND Ein - Eout

1. Acoil - Bcoil = 30mv div

2. VAPOR LEAD \#1 AND VAPOR LEAD $\# 2=220 \mathrm{mv}$ div

3. TOTAL COIL VOLTAGE $=3$ VOLTS

(USING A $200 \mathrm{~A}$ PULSE AT 50AMP/SEC)

[SEE WIRING DIAGRAM]

4. CHECK CAP BANK VOLTS - 45OV

5. DUMP RESISTOR $=0.09 \Omega$

a. DO A 200 AMP DUMP AND CALCULATE

b. DO A 500 AMP DUMP AND CALCULATE

6. CHECK TRANS REX OVER CURRENT LEVEL

B. BE SURE TO RECORD HEATER FIRING INFORMATION.

NOTE: ALL THESE TESTS RUN WITH RE-ENTRY TUBE

PUMPED DURING THE HEATER FIRING SEQUENCE. (SEE POWER SUPPLY CHECK)

1. START AT 100 VOLTS AND INCREASE IN 50 VOLT INCREMENTS UNTIL IT QUENCHES WITH IMAG = 1000 AMPS.

2. RECORD THE VOLTAGE AND THE TEMPERATURE FOR EACH HEATER.

C. QUENCH RUN 4. $2 \mathrm{~K}$ UP TO THE FLAT POINT. (RANDOM RESULT CK SS CURVE PROVIDED ON X - $Y$ RECORDER)

1. AFTER 5TH QUENCH TURN OFF HEATER

D. (ENERGY IN - ENERGY OUT)

1. 4000 AMP CYCLE
A. $12 \mathrm{~A} / \mathrm{SEC}$
D. $100 \mathrm{~A} / \mathrm{SEC}$
B. $24 \mathrm{~A} / \mathrm{SEC}$
E. $200 \mathrm{~A} / \mathrm{SEC}$
C. $50 \mathrm{~A} / \mathrm{SEC}$
F. $300 \mathrm{~A} / \mathrm{SEC}$

G. $400 \mathrm{~A} / \mathrm{SEC}$

2. 5500 AMP CYCLE OR 6500 ON THE SX 100N SERIES

A. $100 \mathrm{~A} / \mathrm{SEC}$

E. PUMP ON MAGNET AND REDUCE TEMPERATURE TO $3.2-3.5 \mathrm{~K}$.

F . QUENCH MAGNET AT SUB-COOLED CONDITION UNTIL IT FLATTENS OUT. (RANDOM RESULT OR REACH SS CURVE)

G. ALLOW MAGNET TO WARM TO 4.2K - CONTINUE TRAINING UNTIL SS CURVE OR FLATTENING OUT IS REACHED.

H. RUN QUENCH VERSUS I FOR:

1. $12 \mathrm{~A} / \mathrm{SEC}$

4. $100 \mathrm{~A} / \mathrm{SEC}$ 

2. $24 \mathrm{~A} / \mathrm{SEC}$
3. $50 \mathrm{~A} / \mathrm{SEC}$
5. $200 \mathrm{~A} / \mathrm{SEC}$
6. $300 \mathrm{~A} / \mathrm{SEC}$

7. $400 \mathrm{~A} / \mathrm{SEC}$

(NOTE: SX10ON MAGNETS - 2)

*NOTE: AT SLOWER SPEEDS, GO TO $90 \%$ OF PEAK AT 100 A/SEC, THEN

PROCEED AT SLOWER RATE AFTER 10 SECOND PAUSE.

I. RUN A CHECK QUENCH AT 12 A/SEC AFTER $90 \%$ TO VERIFY

THE PERFORMANCE. NOTE: PUMP AND PURGE AND PRESSURIZE

THE BORE TUBE. BE SURE TO CHECK TEMPERATURE BEFORE

CHANGING FROM HELIUM TO NITROGEN.

J. SET UP MAGNETOMETER.

1. CHECK VERTICAL HEIGHT TO INDICATOR TO 37CM UNLESS

SPECIFICALLY NOTED DIFFERENTLY

2. CHECK DIPOLE QUAD SWITCH

3. SET ALL GAIN TO 100, EXCEPT THE BASE TERM, I.E., DIPOLE, QUAD

4. RPM COUNTER $=2160$

**K. MEASURE THE HARMONICS FOR AND AFTER ONE CYCLE TO 4000 AMPS AND DOWN.

1. 0 - CURRENT

2. $100,200,300,400,500,600$ AMPS - DC

3. $1000,1500,2000,2500,3000,3500,4000$, 4500,5000 AMPS - DC

4. $4500,4000,3500,3000,2500,2000,1500$, 1000 AMPS - DC

5. $600,500,400,300,200,100$ AMPS - DC

**L. RUN AC HARMONICS (SEE MAC FOR IMPLEMENTATION)

1. $12 \mathrm{~A} / \mathrm{SEC} \quad 50$ - 4000 AMPS

2. $25 \mathrm{~A} / \mathrm{SEC}$

3. $100 \mathrm{~A} / \mathrm{SEC}$

4. $200 \mathrm{~A} / \mathrm{SEC}$

M. RUN D.C. HARMONICS (SEE ABOVE) 5000 OR 6500 ("S" SERIES) A CYCLES

N. RUN A.C. HARMONICS (SEE ABOVE) 5000 OR 6500 ("S" SERIES) A CYCLES * IF YOU FEEL CONFIDENT, GO TO 5000/6500 A CYCLES ONLY.

O. SPECIAL TESTS:

NOTE: CHECK TEAT ALL DATA HAS BEEN TAKEN AND START WARM-UP.

1. WHILE MAGNET IS WARM, MEASURE HARMONICS WITH

THE PROBE AT 360 RPM (2160 BINARY COUNTER), WTTH:

A. *25 AMPS DC AT ROOM TEMPERATURE

B. $\quad 30$ AMPS DC AT $77 \mathrm{~K}$ 
WOTE: TURN DIPOLE COIL GAIN TO 100 DURING THIS PHASE.

**IN THIS CASE, $K$ \& L ARE REPLACED BY $M$ \& $N$ ONLY.

P. CHART RECORDER FOR BOTH LEADS

1. COIL VOLTS A

2. LEAD VOLTS, A \& $B$

3. CURRENT

4. RP CURRENT

5. DIFFERENCE BETWEEN A - B

6. TOTAL VOLTS

7. COIL VOLTS B F

8. SPLICE VOLTS (THROUGH DANA AMP) 